4.

Derecho judiciario 



\title{
LA COMBINACIÓN DE LA ADMINISTRACIÓN PÚBLICA Y PRIVADA DE LA JUSTICIA CIVIL*
}

["The Combination of the Public and Private Administration of Civil Justice"]

\author{
NeIL ANDREws** \\ Clare College, Universidad de Cambridge, Inglaterra
}

\begin{abstract}
RESUMEN
Este artículo resume la tendencia actual y permanente del proceso civil inglés hacia el control y dirección de los procesos judiciales para hacerlos más eficientes evitando las etapas hasta la audiencia de juicio, un mayor rol activo, de dirección y gestión del juez, aplicación de la regla de sin victoria no hay honorarios y finalmente la restricción a los recursos. A esa tendencia se suma la otra hélice la
\end{abstract}

\begin{abstract}
This article summarizes the current and continuous trend of the English civil procedure towards the control and management of court proceedings to make them more efficient by avoiding stages until the trial, by having the judge upholding a greater active role in managing and handling the proceedings by applying the no win no fees rule and, finally, by restricting resources. In addition to this
\end{abstract}

RECiBIDo el 1 de agosto y ACEPTADo el 16 de octubre de 2012.

* Este artículo es una versión ampliada del texto entregado para las clases de Derecho procesal comparado en la Universidad de París I, La Sorbona, en el curso del profesor Loïc Cadiet, el día 12 de abril de 2012.

** Profesor del Clare College de la Universidad de Cambridge. Traducción de Álvaro Pérez Ragone (Pontificia Universidad Católica de Valparaíso) y Ramón García (Universidad de la Santísima Concepción, estudiante del Programa de Doctorado de la PUCV). Ella se inserta en el proyecto FondeCyT regular $\mathrm{N}^{\circ} 1111021$, "Principios de la tutela ejecutiva del crédito". 
segunda tendencia en el mayor uso de los mecanismos no judiciales de resolución de controversias, especialmente la mediación y el arbitraje.

Palabras Clave

Proceso civil inglés - Arbitraje - Mediación y acuerdos. there is another tendency, a helix, a second trend, consisting in an increased use of non-judicial mechanisms for controversies settlement, especially mediation and arbitration.

KEYWORDS

English civil procedure - Arbitration - Mediation and agreements.

\section{INTRODUCCIÓN}

El propósito de este artículo es señalar dos tendencias en el proceso civil que, por cierto, no son peculiares solo de Inglaterra. En primer lugar, se debe remarcar una orientación permanente hacia el control y dirección judicial de los procesos judiciales para hacerlos más eficientes. En Inglaterra, las cuatro principales manifestaciones de la lucha por la dirección del proceso y una mayor eficiencia, son: $i$ ) un prejuicio institucional en contra de la audiencia de juicio (evasión del juicio y promoción de los acuerdos y la mediación); ii) un mayor uso del "case management" (gestión y dirección del proceso) por los jueces; iii) ampliación de la regla "No victory no fee" ("Sin victoria no hay honorarios") como sistema de remuneración de los abogados litigantes, y facilitar asimismo el sistema de asistencia jurídica civil para el acceso a la justicia; y iv) restricciones de los recursos y medios de impugnación. Estos cuatro aspectos se explicarán en la sección III de este trabajo. La segunda tendencia a la que me refiero se manifiesta en el mayor uso de los mecanismos no judiciales de resolución de controversias, y en forma notoria la mediación y el arbitraje. Esta evolución se examinará en las secciones IV y $\mathrm{V}$ de este artículo.

Es tal vez irónico que, a pesar de la intensa actividad destinada a reformar, mejorar y perfeccionar los procesos civiles, la demanda de medios alternativos de justicia civil no haya disminuido, sino que, por el contrario, ha aumentado. De hecho no parece pesimista, sino más bien una conclusión realista y afianzada en una larga experiencia, sostener que los modernos sistemas judiciales (fuentes de "justicia pública") es poco probable que mejoren, a tal punto que la mediación y el arbitraje (fuentes de "justicia privada") puedan dejar de ser formas atractivas y alternativas de justicia.

La perspectiva moderna, pragmática y positiva, es aceptar que los sistemas público y privado son complementarios y se refuerzan mutuamente. Tiene sentido así hablar de un "sistema binario" de "justicia pública y privada". Los desafíos son continuar mejorando todos los elementos del sistema 
binario: por un lado permitiendo que el sistema judicial tenga un mejor desempeño, asegurando que el arbitraje y la mediación serán conducidos justa y eficientemente; y por otro lado promover la coexistencia armoniosa, de un verdadero matrimonio, entre los sistemas público y privado. Será útil pues en la sección II comenzar por consignar brevemente las cuatro formas principales de la justicia civil.

\section{El PANORAMA DE LA JUSTICIA CIVIL}

Las contiendas pueden ser juzgadas por los tribunales, resueltas por arbitraje o por una convención generada en la mediación; también las partes pueden llegar espontáneamente a acuerdos sin mediación. Estas son las "cuatro formas de la justicia civil": los tribunales, el arbitraje, la mediación y la solución de mutuo acuerdo (sin mediación).

De estas cuatro formas, las tres primeras incluyen la referencia a uno o más terceros neutrales: el resultado de tal referencia es tanto que, ese tercero es un factor de decisión: ora por ser él quien decide (sentencia de un tribunal de justicia o laudo por un tribunal arbitral), ora por emplear los buenos oficios para facilitar que las partes por sí mismas decidan y lleguen a un acuerdo.

De las funciones de estos terceros neutrales, el principal contraste se da entre el rol "facilitador" del mediador y la función de toma de decisiones de los otros. El mediador no decide. Dentro de la mediación, solo las partes deciden: si llegan o no a un acuerdo, y, de hacerlo, en cuáles términos. Sin embargo, el árbitro y el juez pueden -de hecho deben- decidir mediante la dictación de un laudo o sentencia que abarque todos los puntos sometidos para su conocimiento y decisión.

\section{LAS CUATRO FACETAS DE LA LUCHA POR EL CONTROL JUDICIAL DEL LITIGIO}

\section{Elprejuicio institucional contra el proceso judicial completo con audiencia} de juicio ("trial").

Los jueces ingleses tradicionalmente han dedicado tiempo para participar en las audiencias de juicio o de recursos. Sin embargo, ambas actividades están en peligro de extinción. Por el contrario, la mayor parte de los procedimientos judiciales tienden a evitar la etapa de juicio y apelación. Los jueces han cambiado su actitud para facilitar y gestionar una salida en base al acuerdo de las partes y otros patrones. Bien podrían sorprenderse aquellos que son ajenos a estas particularidades de la moderna justicia civil en Inglaterra.

¿Será que ya no es la característica principal la audiencia de juicio ("trial")? Después de todo, sería un evento no teatral asistir a una representación del 
"Hamlet" de Shakespeare, en el que el príncipe atribulado ha sido privado de todo guión teatral. Sin embargo, la mayoría de la litigación civil inglesa se produce sin que las partes disfruten de su "día en la corte", "la magna sesión plenaria" conocido en la tradición del "Common Law" como "la audiencia de juicio" ("trial")

En suma, las audiencias de juicios civiles ("trials") son cada vez menos frecuentes (y lo mismo se ha observado en los EE.UU.). Muchos de los procesos concluyen finalmente sin audiencia de juicio. De hecho la mayoría de los litigantes no desean verse envueltos en un proceso civil hasta esa fase. La mayoría de los procesos no llega a la etapa de la audiencia de juicio, debido a que el caso es resuelto de forma sumaria o bien se pone fin a él antes de la audiencia final. Cuando estas rumas de casos con o sin contradictorio con el detalle común que no llegan a audiencia de juicio no son considerados estadísticamente, lo único que queda es un porcentaje relativamente pequeño de procesos en que un juez de primera instancia pronuncia una sentencia definitiva sobre el fondo en una audiencia, después de escuchar la declaración de testigos.

Es cierto que la pieza histórica central del proceso del derecho del "Common Law" ha sido el de "la audiencia de juicio" ("trial"). En las cortes de "Common Law", del siglo XIX, en Inglaterra, el juicio se llevaba en una audiencia oral ante el juez y un jurado. En los Estados Unidos de América el proceso civil por jurados es un derecho constitucional ${ }^{1}$. Sin embargo, Inglaterra ha sido más pragmática. En los tiempos modernos, los procesos civiles en Inglaterra son casi siempre llevados ante un juez sin jurado. El juicio con jurado en Inglaterra se encuentra circunscrito a los casos penales graves (por ejemplo, asesinato, violación, robo a mano armada) y las acciones civiles por difamación (incluso en este caso existe la posibilidad de una audiencia de juicio solo ante un juez $z^{2}$ daños por difamación, calumnias e injurias maliciosas) ${ }^{3}$. Ya en el año 1966, se hizo evidente que los tribunales civiles no estaban dispuestos a dar marcha atrás en la tendencia moderna

\footnotetext{
${ }^{1}$ Sobre la garantía constitucional del juicio por jurado en ciertos casos en USA., Hazard, G. - Taruffo, M., American Civil Procedure (Yale University Press, 1993), pp. 128 ss.

2 "Fiddes v. Channel Four Television Corpn" [2010] EWCA.Civ 730; [2010] 1 WLR. 2245 (Volumen de procesamiento de video del juicio por jurado como material inapropiado).

${ }^{3}$ 69, Senior Courts Act 1981; y 66, County Courts Act 1984; Andrews, N., English Civil Procedure (Oxford University Press, 2003), pp. 34 ss.; Andrews, Neil, Development in English Civil Procedure, How Far Can the English Courts Reform their Own Procedure?, en Zeitschrift für Zivilprozess International, 2 (1997), pp. 3-4. También debe considerarse Jасов, J. I. H., The Fabric of English Civil Justice (1987), pp. 156-1577 notas 16-8. Sobre la antipatía al juicio civil por jurados en el siglo XIX puede
} 
para confinar el juicio por jurados a estas categorías especiales de demandas ${ }^{4}$ (y esto contrasta con la importancia y protección constitucional del jurado en el "Common Law" de los EE. UU.) 5 .

El proceso civil inglés se puede dividir en seis fases, de las cuales apenas la cuarta es la audiencia de juicio ("trial"). Estas seis fases son: $i$ ) la fase anterior y previa al inicio del proceso o de "pre-action"; ii) el inicio; iii) la preparación de la prueba de los hechos sea por declaración de las partes como la pericial; también es importante el intercambio de documentos entre las partes ("divulgación" o "manifestación de documentos" ("disclossure"), antes conocido como etapa de descubrimiento ("discovery"); $i v$ ) audiencia de juicio; $v$ ) recursos; vi) cumplimiento o ejecución de lo decidido. Estas son las seis fases de un litigo civil, en el sentido de que es posible (aunque, por supuesto, no inevitablemente) que un proceso civil puede darse y contener cada una de esas fases.

La atención de este artículo se centra en las tres primeras etapas. Cada una de estas primeras fases de la controversia puede ser considerada no sólo como preparación para el juicio, sino también -y más importante aúncomo una nueva oportunidad para lograr un acuerdo o el desistimiento de la demanda.

\section{Fase 1: La etapa previa al inicio del proceso.}

El sistema de las normas de proceso civil (CPR. de 1998) introdujo un conjunto importante de protocolos previos a la demanda ${ }^{6}$, como se explica en

verse, Getzler, J., Patterns of Fusion, in Birks, P. (editor), The Classification of Obligations (Oxford, Clarendon Press, 1997), cap. $7^{\circ}$, pp. 187 ss.

4 "Ward v. James" (№ 2) [1966] 1 QB 273, CA (aplicado en "H v. Ministry of Defence” [1991] 2 QB 103, CA; “Heil v. Rankin” [2001] QB 272, CA, en [25]); “Aitken v. Preston", The Times, 21 May 1997, CA.

${ }^{5}$ Hazard G. - Taruffo, M., American Civil Procedure (Yale University Press, 1993), pp. 128 ss.

${ }^{6}$ Directivas prácticas de conducta para los protocolos previos a la demanda ("PreAction") enuncia los siguientes en 5.2,

$$
\text { Pre-Action Protocol Vigente desde }
$$

Personal Injury

$$
26 \text { abril de } 1999
$$

Clinical Disputes

26 de abril de 1999

Construction and Engineering

2 de octubre de 2000

Defamation

2 de octubre de 2000

Professional Negligence

16 de julio de 2001

Judicial Review

4 de marzo de 2002

Disease and Illness

8 de diciembre de 2003 
el "Repport" de este autor $(2007)^{7}$. La fase previa abarca el período comprendido entre la preparación del caso, cuando se consideran y se van perfilando las materias pertinentes que integrarán la demanda y contestación, hasta el inicio formal del proceso. La etapa previa es una primera fase de la controversia civil por los siguientes aspectos: $i$ ) esta fase forma parte de una serie de segmentos; ii) la misma está regulada por el sistema de las Civil Procedure Rules (CPR); iii) este régimen se aplica a todas las eventuales demandas en Inglaterra y Gales; iv) existen sanciones aplicables allí consideradas para el caso de que una parte eventual del proceso no cumpla con el conjunto de normas que regulan esta etapa.

Todos los litigios civiles que entran dentro de la competencia de los tribunales ingleses deben primero cumplir con meticuloso sistema de protocolos previos. Estos gobiernan los pasos que deben seguir las eventuales partes en la preparación para el inicio del proceso. Este régimen se aplica a quienes serán eventualmente partes en el proceso, en particular, $i$ ) para comunicarse entre sí la naturaleza de la demanda y contestación antes de la apertura antes del inicio formal de un proceso; $i$ ) considerar la oportunidad para un acuerdo y empleo de las ADR (Alternative Dispute Resolution), en particular la mediación (aunque ésta es en realidad obligatoria de ser intentada); y iii) para hacer intercambios apropiados de información relevante, incluyendo los documentos centrales relacionados con el caso. De ello se desprende que en un proceso grande y complicado podrían transcurrir muchos meses hasta que las partes cumplan con estos requisitos.

Los tribunales se involucran en esta fase previa al momento en el que se hace valer la acción sólo retrospectivamente, una vez que se inicia formalmente el procedimiento. Los jueces se preparan entonces para aplicar sanciones a las partes reticentes en cumplir con los deberes exigidos en los protocolos. En particular, los tribunales están facultados para adecuar las resoluciones que condenan en costas a las partes morosas. Ese ajuste de los costos que genera el proceso podría tener consecuencias económicas muy graves. Por ejemplo, una parte que inste el inicio formal del proceso puede estar expuesta al pago de las costas según examen del tribunal y sobre la base de una indemnización o pagos significativos de intereses de aquellas.

Housing Disrepair

Possession Claims based on rent arrears

Possession Claims based on Mortgage Arrears etc.
8 de diciembre de 2003

2 de octubre de 2006

19 de noviembre de 2008

${ }^{7}$ Cfr. Andrews, Neil, General Report (que examina cerca de veinte jurisdicciones) en esta materia para el Congreso Mundial de Derecho Procesal de Brasil, en Pellegrini Grinover, A. - Calmon, R. (editores), Direito Processual Comparado, XIII Congreso Mundial de Derecho Procesal (Rio de Janeiro, Editora Forense, 2007), pp. 201-242. 


\section{Fase 2: Inicio, postulación, gestión y dirección del proceso.}

El proceso se inicia con la demanda y la resolución como formulario que la contiene emitido por el tribunal. La CPR. 7,2 (1) establece: "El procedimiento se inicia cuando el tribunal emite un formulario de demanda a petición del demandante", de lo que también debe ser notificado el demandado. Aunque en realidad como ya se vio, de hecho la comunicación y notificación entre las partes ya se inicia con antelación.

Cada parte en los procesos civiles ingleses debe presentar una declaración jurada sobre el caso (anteriormente conocida como "pleading" o declaración sobre los escritos de partes). La justificación de la propuesta debe exponer los principales aspectos de la demanda o contestación. El demandante también debe especificar el derecho cuya tutela judicial se busca, como por ejemplo, un crédito, daños y perjuicios, ejecución, medida cautelar, o una mera declaración judicial. No hay necesidad de incluir en esta declaración detalles sobre la prueba o argumentación jurídica.

La gestión y dirección del proceso según el caso ("case management") es la característica más importante de la litigación con alternativas de procedimientos posteriores a seguir o caminos múltiples ${ }^{8}$. El tribunal debe asegurar activamente que los asuntos estén bien enfocados, reducir el margen de las conductas indisciplinadas como los gastos en los que se incurrirá y, al mismo tiempo lograr el avance con la mayor rapidez (ver detalles más abajo).

\section{Fase 3: Preparación de la prueba.}

Esta fase de preparación "para la audiencia de juicio" es en verdad una etapa solo a medias, y por ello podría conducir a error en su calificación. La realidad es que cada aspecto de la "preparación" (preparación de documentos, revelación o exhibición, las declaraciones de los testigos sobre hechos, las referencias a los peritos) tiene una doble vida: de hecho es una preparación para la siguiente etapa formal de litigio (audiencia de juicio). Pero también es una nueva oportunidad para que las partes puedan evaluar la fuerza de sus respectivos casos mostrando todas las cartas que es en realidad lo que implicará la prueba recopilada. Ello permite revisar y reconsiderar las ofertas de acuerdos, para reducir o resolver sus diferencias, y por lo tanto evitar el enfrentamiento cara a cara exponiendo todas las cartas que implica la prueba.

La situación es análoga a los estudiantes de doctorado que buscan obtener algo en sus días de estudiante, sólo con la esperanza de lograr en realidad

\footnotetext{
${ }^{8}$ Sobre el Nuevo sistema desde la perspectiva del tradicional principio adversarial, Andrews, Neil, A New Civil Procedural Code for England, Party-Control Going, Going, Gone, en Civil Justice Quarterly, 19 (2000), pp. 19-38; ANDrews, Neil, English Civil Procedure (Oxford University Press, 2003), 13. 12 a 13. 41; 14. 04 a 14. 45; 15. 65 a 15.72.
} 
otra cosa, mejor que un grado de doctor a obtenerse por mientras. Tal vez el estudiante encontrará una vida fuera de la investigación. Si es así, incluso quizás ese grado no hubiera sido necesario. Esta es la visión de la gran mayoría de los litigantes que participan en estas diligencias previas: la esperanza de que algo va a suceder y que evitará el llegar a audiencia de juicio.

a) La divulgación o revelación de documentos. La manifestación recíproca de documentos logra la igualdad de acceso a la información, facilita una mejor solución de los conflictos, y evita el "juicio por emboscada" (donde una parte no es capaz de responder adecuadamente a una revelación sorpresiva en la audiencia final). Después de iniciado el proceso, cada parte debe preparar una lista de documentos en los que se basará, o que puedan ayudar a la otra parte ${ }^{9}$, y debe permitir que el oponente tenga acceso a estos documentos ${ }^{10}$. Dicha información sólo se convierte en evidencia si es "aportada" por una de las partes para que sea producida en una audiencia de juicio u otro tipo de "audiencia probatoria". El destinatario de la información manifestada o divulgada por imperativo legal sólo puede emplearla para esas actuaciones, no pudiendo ser revelada a terceros ${ }^{11}$.

b) Preparación de las partes sobre los hechos objeto de prueba. En el proceso civil inglés la "recopilación de pruebas" y la "preparación de la evidencia” están controladas por las partes, con sujeción solamente a las instrucciones que dé el juez sobre la dirección y manejo del proceso según sea el caso. Por lo tanto el tribunal no obliga a las partes a presentar testigos o documentos particulares. Las partes también seleccionan a los peritos propios para el proceso. Cada parte es competente para declarar como testigo sobre "hechos", es decir, evidencia de lo que cada cual vio o escuchó. Cada parte produce normalmente una prueba testimonial con declaraciones en relación a los hechos, incluida la propia de la parte si ésta tiene la intención de actuar como testigo. Ningún testigo puede ser escuchado a menos que su declaración haya sido intercambiada antes de la audiencia de juicio. Se espera así que el juez haya leído las declaraciones de los testigos antes del juicio. Luego en la audiencia de juicio esta prueba puede ser complementada con el interrogatorio oral.

c) Evidencia especializada y conocimientos técnicos ${ }^{12}$. No hay

${ }^{9}$ CPR. Part 31

${ }^{10}$ CPR. 31. 10 (2) y 31. 15, sujeto a ciertas calificaciones agregadas por CPR. 31. $3(2)$.

${ }^{11}$ CPR. 31. 22; Lord Hoffmann in "Taylor v. Serious Fraud Office" [1999] 2 AC 177, 207, HL; "Smith Kline Beecham Biologicals SA v. Connaught Laboratories Inc" [1999] 4 All ER 498, CA.

${ }^{12}$ Dwyer, D., The Judicial Assessment of Expert Evidence (Cambridge, Cambridge University Press, 2008), en cuyas pp. 88 ss. se contiene una discusión sobre el Dere- 
prueba pericial que se pueda presentar en un caso a menos que el tribunal la haya admitido y formalmente conceda permiso para ello $^{13}$. La prueba pericial puede ser admitida bajo dos modalidades: sea mediante un "experto único y conjunto", o bien por peritos designados individualmente por las partes, o por los asesores del tribunal ${ }^{14}$. El uso de peritos individuales y conjuntos es una gran innovación del sistema del CPR. Este experto actúa en forma conjunta para ambas partes que asumirán su costo y es más probable que goce de neutralidad y objetividad. Sin embargo, el principal problema con el sistema de experto individual y conjunto es el peligro de la falta de precisión, los peritos son falibles. Por esta razón, la mejor y correcta interpretación es que el derecho inglés ha reservado este sistema de designación de peritos por las partes solo para los casos o procesos complejos; o bien como una "red de seguridad" en caso de que la prueba de perito único sea insatisfactoria en los casos donde más aplicación tiene, los de menos importancia ${ }^{15}$.

Por contraste, la prueba de peritos nombrados por las partes podría ser un traje a la medida en favor de quien lo designó ${ }^{16}$. Pero no debe olvidarse que los tribunales están acostumbrados a tamizar, pesar, y desechar. El sistema de peritos designados por las partes puede inyectar un escepticismo y coadyuvar a un saludable debate que, a través de la colisión de puntos de vista opuestos con "honestidad intelectual" permita en el proceso tomar una "visión" sobre asuntos opinables y discutibles. Este punto fue subrayado por el profesor Hazard en el proyecto de Principios de proceso civil transnacional del UNIDROIT ${ }^{17}$.

cho comparado; Blom-Cooper, L. (editor), Experts in Civil Courts (Oxford, Oxford University Press, 2006); ANdrews, Neil, The Modern Civil Process (Tübingen, Mohr \& Siebeck, 2008), cap. $7^{\circ}$; ANDrews, Neil, English Civil Procedure (Oxford, Oxford University Press, 2003), cap. $32^{\circ}$.

${ }^{13}$ CPR. 35. 4 (1) a (3).

${ }^{14} \mathrm{El}$ sistema del asesor del tribunal es de importancia menor, y se encuentra restringido para colisiones marítimas, disputas por patentes, y problemas de costos, ANDrews, Neil, The Modern Civil Process (Tübingen, Mohr \& Siebeck, 2008), 7. 04.

${ }^{15}$ Para detalles, ANDrews, Neil, cit. (n. 14) 7. 13, 7.14,

${ }^{16}$ Sir Thomas Bingham MR in "Abbey National Mortgages plc v. Key Surveyors Ltd” [1996] 1 WLR 1534, 1542, CA (a pre-CPR. case concerning appointment of a court expert under the old RSC Ord 40).

${ }^{17}$ Principio 22. 4; disponible en, http,//www. unidroit. org/english/principles/civilprocedure/main. htm. También publicado como American Law Institute/ UNIDROIT'S Principles of Transnational Civil Procedure (Cambridge, Cambridge University Press, 2006). 


\section{Dirección y gestión del proceso ${ }^{18}$.}

Esta forma de gestión y dirección del proceso civil cuenta con apoyo internacional. Los (no vinculante) Principios de proceso civil transnacional del UNIDROIT recomiendan ${ }^{19}$ que el juez debe gestionar y dirigir activamente el proceso, mediante el ejercicio de facultades discrecionales para lograr la solución de la disputa de manera justa, eficiente y con una celeridad razonable"20.

Los tribunales ingleses poseen amplios "poderes de gestión y dirección de los casos sometidos a su conocimiento". En su informe de 1995-199621, Lord Woolf adoptó esta técnica como el pilar del sistema de "multi-track", múltiples caminos o salidas, lo que incluye a todos los procedimientos del Tribunal Superior ${ }^{22}$ (los litigios del tribunal de condado con mayor costo y todos los del Tribunal Supremo).

La dirección y gestión del proceso tiene tres finalidades principales: alentar e instar a las partes a una mediación ${ }^{23}$, donde sea ello factible; en segundo lugar impedir que el caso avance con demasiada lentitud o con deficiencias; y por último, garantizar que los recursos e insumos judiciales se repartirán proporcionalmente, ello según lo requerido en la parte CPR. 1. Allí se exige que el tribunal y las partes deben considerar sus demandas en competencia o concurrencia con relación a otros litigantes actuales o eventuales que deseen tener acceso a la justicia, en vista de los "escasos recursos" de los Tribunales

${ }^{18}$ Sobre el Nuevo sistema desde la perspectiva del tradicional principio adversarial, Andrews, Neil, A New Civil Procedural Code for England, Party-Control “Going, Going, Gone”, en Civil Justice Quarterly, 19 (2000), pp. 19-38; ANDrEws, Neil, English Civil Procedure (Oxford, 2003), 13. 12 a 13.41; 14.04 a 14.45; 15.65 a 15.72.

${ }^{19}$ Principio 14. 1; disponible en, http,//www. unidroit. org/english/principles/civilprocedure/main. htm. Also published as American Law Institute/UNIDROIT's Principles of Transnational Civil Procedure (Cambridge University Press, 2006), 33-4.

${ }^{20}$ Ibíd., Principio 14. 1; La dirección del proceso ("case-management") debe ser conducido con consulta de las partes (Principio 14. 2; y ello impone la necesidad de calendarizar, Principio 14. 3.

${ }^{21}$ Los dos informes de Lord Woolf son, Access to Justice, Interim Report (1995), y Access to Justice, Final Report (1996); para comentarios, Zuckerman, A. - CransTON, R., The Reform of Civil Procedure, Essays on 'Access to Justice' (Oxford, Oxford University Press, 1995); Cranston, R, How Law Works (Oxford, Oxford University Press, 2006), cap. $5^{\circ}$.

${ }^{22}$ Cfr. Andrews Neil, English Civil Procedure (Oxford, Oxford University Press, 2003), capítulos $13^{\circ}, 14^{\circ}$ y $15^{\circ}$; Zuckerman on Civil Procedure (London, 2006), en 1. 74 ss., capítulo $10^{\circ}, 11^{\circ}, 53$ ss.

${ }^{23}$ En general, Mackie, K. - Miles, D. - Marsh, W. - Allen, T., The ADR Practice Guide (London, 2007), caps. $5^{\circ}, 6^{\circ}$ y $7^{\circ}$; ANDrews, Neil, cit. (n. 14), cap. $11^{\circ}$; Andrews, Neil, Contracts and English Dispute Resolution (Tokyo, 2010), cap. $22^{\circ}$. 
de Justicia ${ }^{24}$. Así en las CPR. se enumeran las siguientes responsabilidades de gestión y dirección de los jueces, sin que con ello se pretenda ser exhaustivo con las diferentes formas que pueda asumir el rol activo del tribunal ${ }^{25}$.

a) Impulso del proceso: El tribunal debe fijar (en consulta con las partes y sus abogados) el tiempo, calendarizando las actividades y en general controlar el progreso del caso ${ }^{26}$. Se deben dar instrucciones en el sentido que el proceso se llevará tan rápida y eficientemente como sea posible ${ }^{27}$.

b) Cooperación y acuerdo. Los tribunales deben alentar a las partes a cooperar ${ }^{28}$, ayudar a resolver la totalidad o parte de la causa ${ }^{29}$, y promover la resolución alternativa de conflictos ${ }^{30}$, donde ella sea apropiada. Para ello el tribunal tiene la facultad de suspender el procedimiento para permitir las negociaciones extra-procesales ${ }^{31}$.

c) Determinación de la relevancia y fijación de las prioridades. El tribunal debe ayudar a identificar los problemas centrales en el caso $^{32}$. Esto incluye la facultad de excluir cuestiones que sean irrelevantes ${ }^{33}$. El tribunal debe decidir el orden en que los asuntos deben ser resueltos ${ }^{34}$. Se debe tratar de determinar lo más pronto posible aquellos problemas que necesitan de un proceso completo de los que pueden resolverse sumariamente ${ }^{35}$.

d) Generación de decisiones sumarias. El tribunal debe decidir si se inicia una audiencia sumaria (de acuerdo al CPR., parte $\left.24^{a}\right)^{36}$, o si la demanda o defensa carecen de posibilidad de éxito, ${ }^{37} \mathrm{o}$ si debe decidirse y resolverse alguna cuestión preliminar ${ }^{38}$.

e) Regulación de gastos. El tribunal debe decidir si una medida pro-

${ }^{24}$ Andrews, Neil, English Civil Procedure (Oxford, Oxford University Press, 2003), caps. $13^{\circ}, 14^{\circ}$ y $15^{\circ}$; EL MIsmo, Zuckerman on Civil Procedure (London, 2006), pp. 1.74 ss., caps. $10^{\circ}$ y $11^{\circ} 53$ ss.

${ }^{25}$ CPR. 1. 4 (2); CPR. 3. 1 (2); CPR. partes 26, 28, 29.

${ }^{26}$ CPR. $1.4(2)(\mathrm{g})$.

${ }^{27}$ CPR. $1.4(2)(1)$.

${ }^{28}$ CPR. 1.4 (2) (a).

${ }^{29}$ CPR. $1.4(2)(\mathrm{f})$.

${ }^{30}$ CPR. $1.4(2)(\mathrm{e})$.

${ }^{31}$ CPR. 3.1 (2) (f).

${ }^{32}$ CPR. $1.4(2)(a)$.

${ }^{33}$ CPR. 3.1 (2) (k).

${ }^{34}$ CPR. 1.4 (2) (d); 3.1 (2) (j).

${ }^{35}$ CPR. $1.4(2)(\mathrm{c})$.

${ }^{36} \mathrm{PD}$ (26) 5. 1, 5.2

${ }^{37}$ CPR. 3.4 (2).

${ }^{38}$ CPR. 3.1 (2) (1). 
puesta en el proceso es rentable en la relación costos-beneficios ${ }^{39}$, teniendo en cuenta la importancia de la demanda ("proporcionalidad") ${ }^{40}$.

Una parte debe obtener primero la admisión de su recurso contra la resolución del inferior (o permiso para poder apelar), incluyendo aquellas decisiones sobre la dirección y gestión del proceso. Si el juez de primera instancia rechaza el recurso, la Corte de Apelación puede decidir por sí mismo si se lo concederá. Las normas que rigen esta vía son restrictivas. Ello hace que sea improbable un recurso exitoso contra las resoluciones sobre gestión y dirección del proceso ${ }^{41}$. Incluso si se admite el recurso, las cortes de apelaciones están dispuestas a mostrar deferencia considerable a los jueces que pronunciaron las resoluciones sobre gestión y dirección en ese caso, incluidas las relativas a la práctica de la prueba. Por el contrario los jueces del tribunal de apelación dejarán sin efecto las decisiones recurridas si son incorrectas, en principio, o sobre la base de no haber considerado todos los factores pertinentes, o por ser motivadas por una consideración irrelevante, $o$ bien cuando el juez no haya comprendido la finalidad de dichas decisiones ${ }^{42}$. Como ejemplo, aunque inusual, un juez de primera instancia que intervino en las etapas posteriores del litigio criticó al Tribunal de Apelación sosteniendo que había incurrido en un error de procedimiento al desechar una resolución anticipadas obre dirección y gestión del proceso relacionada con la rectificación y corrección de los escritos iniciales del proceso, me refiero al caso "Nottingham shire Gladman Properties Ltd" (2011) ${ }^{43}$.

Una declaración influyente es la formulada por Lord Woolf, en el caso "Biguzzi” (1999): “[...]los jueces tienen que tener confianza para ejercer las

\footnotetext{
${ }^{39}$ Por ejemplo la sugerencia de que las videos-conferencias sean empleadas en los recursos breves, "Black v. Pastouna” [2005] EWCA Civ 1389; [2006] CP Rep 11, per Brooke LJ.

${ }^{40}$ CPR. $1.4(2)$ (h) y 1.1 (2) (c).

${ }^{41} \mathrm{PD}$ (52) 4. 4, 4. 5, Las decisiones sobre dirección formal y material del proceso ("Case-management") incluyen decisiones hechas sobre la base de la regla 3.1 (2) [que contiene una larga lista de facultades procesales] y decisiones acerca del descubrimiento, contenido de las declaraciones de los testigos, informes periciales, calendarización de la demanda, admisión de una parte a la demanda, y costos. En este contexto, la decisión de permitir una apelación requiere considerar 'si el asunto es de suficiente relevancia para justificar los costos de la apelación', 'las consecuencias procesales de la apelación (p. ej., pérdida del día asignado para el juicio) pesan más que la importancia de la decisión de dirección formal y material del proceso, y si esto sería más conveniente para la determinación del asunto en o después de la audiencia de juicio'.

42 “Thomson v. O'Connor" [2005] EWCA Civ 1533 p. [17] a [19], per Brooke LJ; ver también los autores citados en ANDrews, N, English Civil Procedure (Oxford, Oxford University Press, 2003), 13.61 a 13. 68, 38. 49; Zuckerman on Civil Procedure (2006), 23. 193 ss.
}

${ }^{43}$ [2011] EWHC 1918 (Ch); [2011] 1 WLR 3235 
facultades discrecionales amplias que consideren como justas y equitativas [...] [los tribunales] de apelación no deben interferir si los juecespueden demostrar que han ejercido sus poderes de alguna manera, que contraviene los principios pertinentes" ${ }^{\prime 4}$.

$f)$ ¿Cuán sólidas deben ser las sanciones procesales? El enfoque "disciplinario". En una serie de estudios críticos, Adrian Zuckerman se ha quejado de que los tribunales no han demostrado ser coherentes y lo suficientemente fuertes en su rol disciplinario como en el ejercicio de sus facultades de gestión y dirección del proces $\mathrm{o}^{45}$. En particular, sostiene que han mostrado una clemencia indebida hacia el defecto procesal. En su opinión, los tribunales se equivocan al aliviar a las partes y sus abogados de no cumplir eficientemente con el marco procesal y con las órdenes específicas que se emiten como parte de las facultades de los tribunales en materia de dirección y control del proceso.

g) El contra-argumento en favor de la clemencia mesurada y responsable. Podría sugerirse que es importante aplicar el concepto de "equidad procesal" ${ }^{46}$. Tres sentencias judiciales recientes proclaman el valor de la clemencia como contrapeso a un régimen de "tolerancia cero" frente a las inconductas procesales:

"La justicia debe, en su caso, ser sazonada con misericordia" (2011, QC, juez Hodge) ${ }^{47}$.

"[La] tendencia de las CPR. a imponer castigos por los errores y fatalmente

44 "Biguzzi v. Rank Leisure plc" [1999] 1 WLR 1926, 1934 F (CA).

${ }^{45}$ Zuckerman, A. A. S, Litigation Management under the CPR, a Poorly-used Management Infrastructure, en DWYER, D. (editor), The Civil Procedure Rules, Ten Years On (Oxford, Oxford University Press, 2010), p. 89; El mismo, en Andenas, M. - ANDREws, N. - NAzzInI, R. (editores), The Future of Transnational Commercial Litigation, English Responses to the American Law Institute/UNIDROIT Draft Principles and Rules of Transnational Civil Procedure (London, British Institute of Comparative and International Law, reimpresión 2006), cap. $12^{\circ}$; y en Trocker, N. - VARAno, V. (editores), The Reforms of Civil Procedure in Comparative Perspective (Torino, 2005), pp. 143 y ss.; y Zuckerman on Civil Procedure ( $2^{\mathrm{a}}$ edición, 2006), cap. $10^{\circ}$, especialmente en $10.139 \mathrm{y}$ 10.164 ss.; Piggott, D., Relief from Sanctions, en Civil Justice Quarterly (2005), pp. 103.

${ }^{46}$ Andrews, Neil, English Civil Procedure (Oxford, Oxford University Press, 2003), 6. 66 ss.; por ejemplo, "Keen Phillips (A Firm) v. Field” [2006] EWCA Civ 1524; [2007] 1 WLR 686 at [18]; "Estate Acquisition and Development Ltd v. Wiltshire” [2006] EWCA Civ 533; [2006] CP Rep 32; “Horton v. Sadler” [2006] UKHL 27; [2007] 1 AC 307; "Baldock v. Webster" [2004] EWCA Civ 1869; [2006] QB 315; pero esto tiene límites, que se ven, p. ej. en "Olafsson v. Gissurarson” [2006] EWHC 3162 (QB); [2007] 1 All ER 88 (una notificación nula en Islandia no podría sanearse según la regla CPR. 3. 10).

${ }^{47}$ Judge Hodge QC, integrando como juez la High Court, y citado en apelación 
frente al incumplimiento de las normas debe considerar, si esos errores y los asuntos relativos al incumplimiento, pueden ser abordados sin ocasionar una injusticia a la otra parte" (2011, Peter Smith j. ) ${ }^{48}$.

"Existe, por supuesto, el argumento (posiblemente) nuevo en la era de la CPR., que enfatiza la importancia de cualquier mal uso de los recursos de los tribunales. Es bueno tener en cuenta el importante interés público ligado al uso eficiente de estos recursos limitados. Sin embargo, imponer ese interés, en estos casos como un sustituto de la doctrina del abuso procesal es -según mi opiniónuna visión disciplinarista de las reglas procesales civiles quepuedeponer en riesgo la imperiosa necesidad de hacer justicia" (2010, Rix LJ) ${ }^{49}$.

Esta visión también concuerda con los Principios de Procedimiento Civil Transnacional delUnidRoITque recomiendan ${ }^{50}$ :"Las sanciones deben ser razonables y proporcionales a la gravedad del asunto planteado y el daño causado, con consideración del grado de participación y si la conducta fue deliberada o no".

b) Programación de casos ("Docketing”). Lord Neuberger RM, en una reciente conferencia ${ }^{51}$, consideró la programación de los casos, como una propuesta de intensificación de la gestión y dirección del proceso según el caso concreto refiriendo a los procesos especialmente complejos con multiplicidad de salidas o alternativas procedimentales. La programación de los procesos implica que ciertos jueces se hagan cargo del caso, desde su inicio y hasta el juicio, incluida la conducción del proceso. Él dijo ${ }^{52}$ : "como una revolución en nuestro enfoque sobre la conducción de los litigios civiles, la introducción plena de la gestión y dirección del proceso aun está sin terminar. Se trata de la introducción de una forma de programación o, en los términos del Informe Jackson, de "medidas [...] adoptadas para promover la asignación $y$ distribución de los casos a los jueces con experiencia relevante", lo que ayudará a completar la revolución". Lord Neuberger también se refirió a los resultados

posterior en "Pannone LLP v. Aardvark Digital Ltd" [2011] EWCA Civ 803; [2011] 1 WLR 2275, at [23].

48 "Nottinghamshire \& City of Nottingham Fire Authority v. Gladman Properties Ltd” [2011] EWHC 1918 (Ch); [2011] 1 WLR 3235, at [33], per Peter Smith J.

49 “Aktas v. Adepta” [2010] EWCA Civ 1170; [2011] QB 894, [92].

${ }^{50}$ Principio 17.2, disponible en http,//www. unidroit. org/english/principles/civilprocedure/main. htm. También publicado como American Law Institute/UNIDROIT'S Principles of Transnational Civil Procedure (Cambridge, Cambridge University Press, 2006), p. 38.

${ }^{51}$ Docketing, Completing Case-management's Unfinished Revolution (2012), http,// www. judiciary. gov. uk/Resources/JCO/Documents/Speeches/mor-speech-solicitors-cost-conference-lecture-feb2012. pdf

${ }^{52}$ Cit. (n. 52) p. [15] (refiriendo a Sir Rupert Jackson, "Review of Civil Litigation Costs, Final Report" (December 2009), vol. II, p. 469). 
alentadores obtenidos en un proyecto piloto de Leeds ${ }^{53}$, y las experiencias dentro del proyecto de mejora de las Tecnologías de la Comunicación y los tribunales ${ }^{54}$, y para descartar los cambios en el Juzgado de lo Mercantil ${ }^{55}$, así como la experiencia en los EE.UU. ${ }^{56}$.

Lord Neuberger RM identificó los cuatro principales beneficios:

i) El hecho de que los jueces, según se sabe, al inicio del proceso en cada fase serán agudos al exigir a los abogados el cumplimiento de los plazos determinado ${ }^{57}$;

ii) Se gastará menos tiempo judicial en "ponerse al día" adquiriendo familiaridad con los detalles del caso ${ }^{58}$;

iii) La gestión y dirección de casos como las decisiones que se tomen estarán mejor informadas, y las decisiones "formateadas" disminuirán", lo que está conectado a la observación de que los casos complejos requieren una gestión de casos más a la medida ${ }^{60}$;

iv) El proceso será más coherente, en lugar de ser objeto de diferentes intervenciones judiciales, de manera espasmódica e irregular ${ }^{61}$.

Otros puntos mencionados por Lord Neuberger son:

v) Se pueden llevar adelante medidas activas para insistir en el estricto cumplimiento de un riguroso calendario ${ }^{62}$;

vi) El valor de la "proporcionalidad" puede determinarse de una forma más concreta, ya que el juez se asegurará que ese proceso se adecue sólo a lo necesario y rentable;

vii) No se permitirá el serpenteo para luego recoger los escombros a medida que avanza lentamente el juicio ${ }^{63}$, en verdad, una mayor disciplina de los tiempos garantizará concentrarse en lo esencial del caso;

viii) A "falta de tiempo se concentra la mente", y ésta controlará "los cantos de sirena de las horas facturadas" ${ }^{14}$.

${ }^{53}$ Cit. (n. 53), p. [26], citando el estudio de 2012.

${ }^{54}$ Cit. (n. 53), p. [27], resaltando la experiencia de Sir Rupert Jackson en la corte entre 2004 y 2007.

${ }^{55}$ Admiralty and Commercial Courts Guide (2011), section D4, pp. 25-26.

${ }^{56}$ Cit. (n. 53), p. [17], y especialmente p. [20], Citando material de los EE.UU.

${ }^{57}$ Cit. (n. 53), p. [15].

${ }^{58}$ Cit. (n. 53), p. [22].

${ }^{59}$ Cit. (n. 53), p. [22].

${ }^{60}$ Cit. (n. 53), p. [22].

${ }^{61}$ Cit. (n. 53), p. [24].

${ }^{62}$ Cit. (n. 53), p. [24].

${ }^{63}$ Cit. (n. 53), p. [25].

${ }^{64}$ Cit. (n. 53), p. [21]. 
ix) La temprana identificación de los asuntos controvertidos proveerá una sólida base para un acuerdo entre las partes más temprano ${ }^{65}$.

\section{Costos Y FINANCIAMIENTO: TIEMPO DE CAMBIOS}

En un "Estudio de costos en la litigación civil", Lord Justice Jackson (2009-2010) ${ }^{66}$ sometió a examen todo el tema de los costos y financiamiento de la Justicia. Las "Reformas de Woolf" (1994-1999) esperaban aliviar el problema de los altos costos de la litigación civil. Sin embargo, la situación no mejoró.

En una reciente conferencia (2012), Lord Neuberger MR concluyó ${ }^{67}$ :"En los últimos diez años, los costos de la litigación civil han continuado incrementándose. A este respecto la reforma Woolf tenía como uno de sus principales objetivos proveer una cura para los excesivos costos del litigio, pero fracasó. En verdad, lamento decir que las reformas de Woolf son generalmente pensadas para incrementar los costos de litigación. Ciertamente, las reformas [...] se caracterizan por tener delante la composición de costos, lo cual es especialmente lamentable dado que la gran mayoría de los casos se resuelven antes de arribar a audiencia de juicio".

Lord Neuberger MR, en la misma conferencia (2012) ${ }^{68}$ citó al distinguido profesional Geofrey Bindman, cuyas observaciones ${ }^{69}$ anteriores a las CPR. siguen siendo relevantes: "El secreto, quizás medio percibido en este momento, era el carácter abierto a la indefinición de la litigación. El mayor trabajo becho, generaba más pago, y no habia limites para la cantidad de trabajo que se

${ }^{65}$ Cit. (n. 53), p. [21].

${ }^{66}$ JaCKson, Rupert, Review of Civil Litigation Costs (London, 2010); ZuCKerman, A. A. S., The Jackson Final Report on Costs-Plastering the Cracks to Shore up a Dysfunctional System, en Civil Justice Quarterly, 29 (2010), p. 263; McIvor, Claire The Impact of the Jackson Reforms on Access to Justice in Personal Injury Litigation, en Civil Justice Quarterly, 30 (2011), p. 411; para una discussion sobre el costo de las acciones por difamación, Howarth, D., 'The Cost of Libel Actions, A Sceptical Note' [2011] CLJ 397, concluyendo en p. 419 no hay un soporte empírico de que los costos de los casos sobre difamación estén fuera de control (análisis frío y puro sobre Jackson, Review of Civil Litigation Costs, Preliminary Report, Appendix 17, desarrollado por Media Lawyers Association's 154, media cases of 2008; Larson, T. - LeONARdi, D., A Comparative Study of Costs in Defamation Proceedings across Europe (Programme in Comparative Media Law and Policy, Centre for Socio-Legal Studies, University of Oxford, December 2008).

${ }^{67}$ Titulada Docketing, Completing Case-management's Unfinished Revolution (2012), p. [3], http,//www. judiciary. gov. uk/Resources/JCO/Documents/Speeches/ mor-speech-solicitors-cost-conference-lecture-feb2012. pdf

${ }^{68}$ Cit. (n. 53), p. [34].

${ }^{69}$ Bindman, G., No Expense Spared' (1992) New LJ at 1618. 
podia hacer, incluso justificado. Los Barristers fueron alentados (como si ellos necesitaran tal estimulo) a unirse a la diversión. Más recientemente el perro comenzó a mover la cola. Las máquinas de litigación en las grandes firmas tuvieron que ser abastecidas. Todos los casos tuvieron que ser ampliados para ocupar los recursos disponibles para trabajar en esto. El modelo establecido por las firmas más grandes tuvo que ser seguido por todos los demás. No obstante muchas cartas provenian de un lado, la otra tuvo que contestar [...] al igual que un abogado no puede permitirse el lujo de dejar sin respuesta un punto considerado por su oponente. Al elegir invertir mucho dinero en el caso, el otro tenía que igualarlo o bien ir al paredón".

Tampoco las observaciones de Lord Neuberger, recién citadas, son una crítica solitaria a la justicia. Anteriormente, Buxton LJ pronunció esta "crie de coeur" en la Corte de Apelaciones en "Willis v. Nicolson" (2007): "Elalto costo de los litigios civiles en Inglaterra y Gales es un motivo de preocupación no sólo para las partes en un caso particular, sino para el sistema de litigación en su conjunto... Un elemento en el alto costo actual del litigio es, sin duda, la expectativa de los ingresos anuales de los profesionales que lo conducen. El sistema de costos, como opera en la actualidad no puede hacer nada al respecto, ya que evalúa la carga de trabajo sobre la base de las tarifas de mercado que cobran las profesiones, en vez de intentar la tarea, sin duda, dificil de colocar un valor objetivo al trabajo"70.

Las dos principales recomendaciones sobrevivientes formuladas por Sir Rupert Jackson en su "Estudio de costos en la litigación civil: Informe final" ${ }^{71}(2009-2010)$ son:

i) El honorario sujetos a éxito y la ATE "Premium" ("Seguro de defensa jurídica después del evento") dejaría de ser recuperada por la parte victoriosa de la parte vencida en el pleito financiado por CFA (acuerdo de honorarios condicionales), aunque el cliente del proceso donde salió victorioso necesitaría pagar a su abogado dicho honorario por el éxito obtenido;

ii) Los acuerdos de honorarios de contingencia (quota litis), al estilo de Estados Unidos serían legales, es decir, los abogados victoriosos recibirían un porcentaje de la porción de la torta de la victoria (limitado a un máximo del 25 por ciento en los casos de daños y perjuicios), pero el nivel del honorario sería regulado; un demandado vencido sería responsable de pagar a la parte victoriosa los costos ordinarios (en lugar del porcentaje del honorario por el éxito obtenido).

Las recomendaciones del reporte de Jackson han sido fuertemente cri-

70 “Willis v. Nicolson" [2007] EWCA Civ 199 [24].

${ }^{71}$ Sir Rupert Jackson, Review of Civil Litigation Costs, Final Report (2010). 
ticadas por Zuckerman en Civil Justice Quaterly ${ }^{72}$. Sin embargo, a pesar de estas críticas, y tras una consulta general, ${ }^{73}$ el Gobierno anunció en 2011 (comunicado de prensa de 29 de marzo de 2011 del Ministerio de Justicia, Londres) que aplicaría las principales propuestas del informe de Jackson ${ }^{74}$. Estos cambios (aún en trámite ante el Parlamento al momento de escribir este artículo: principios de abril de 2012) figuran en la $2^{\text {a }}$ parte del Proyecto de asistenciajurídica, sentencia y castigo de los delincuentes ${ }^{75}$. En una conferencia (2012) Lord Neuberger MR sugirió que "la gran mayoría de las reformas, que suponían próxima aprobación parlamentaria, entraran en vigor a partir de abril del $2013^{\prime 76}$.

\section{AdMISIÓN DE LOS RECURSOS}

Hay sólidas razones para restringir las apelaciones (recursos en general). Las apelaciones son caras, causan retrasos e implican duplicidad. Como observó Sharpe (Canadá) “el sistema judicial se paralizaría si las partes pudieren apelar todas las decisiones a lo largo del camino. Una parte más fuerte y rica, podría vencer a un oponente por la interposición de una serie interminable de apelaciones. Las exigencias de finalidad y eficiencia prevalecen, y el único responsable de decidir determinadas cuestiones es siempre en definitiva el juez de primera instancia" 77 .

En efecto, en una sentencia del año 2000, Sir Henry Brooke, un influyente juez durante el período de la reforma de Woolf, dijo que "la idea central de la [CPR.] era en disfavor de los recursos que se interponían en contra las resoluciones de los jueces sean o no de distrito" ${ }^{\prime 7}$.

${ }^{72}$ Zuckerman, A. A. S., The Jackson Final Report on Costs-Plastering the Cracks to Shore up a Dysfunctional System, en Civil Justice Quarterly, 29 (2010), p. 263.

${ }^{73}$ Propuestas para una reforma de la litigación civil, financiamiento y costos en Inglaterra y Gales (Consultation Paper 13/10, November 2010, Cm 7947). http,// www. justice. gov. uk/docs/jackson-consultation-paper. pdf

${ }^{74} \mathrm{http}, / /$ www. justice. gov. uk/news/press-release-290311a. htm

$75 \mathrm{http}, / /$ www. publications. parliament. uk/pa/bills/lbill/2010-2012 /0135/2012135. 32-38. html\#j334

${ }^{76}$ Conferencia titulada, Docketing, Completing Case-management's Unfinished Revolution (2012), p. [3], http,//www. judiciary. gov. uk/Resources/JCO/Documents/ Speeches/mor-speech-solicitors-cost-conference-lecture-feb2012. pdf

${ }^{77}$ Sharpe, R. J., Judicial Discretion [1998] Advocates Society J (Canadá) 4, 8.

78 "Copeland v. Smith (Practice Note)" [2000] 1 WLR 1371, CA, per Brooke LJ, comentario hecho en el contexto del imperfecto argumento legal del abogado en primera instancia; véase también "Colley v. Council for Licensed Conveyancers" [2001] 4 All ER 998, CA, p. [46]. 
Casi todos los recursos ${ }^{79}$ requieren que el tribunal otorgue su permiso o los admita (antes conocido como "leave"), en respuesta a la rápida solicitud del recurrente al tribunal de primera instancia (normalmente dentro de los veintiún días; ${ }^{80}$ un período que no puede ser prorrogado por acuerdo de las partes) ${ }^{81}$. Si el tribunal inferior rehúsa admitir el recurso, puede efectuarse una nueva solicitud, esta vez directamente ante la Corte de Apelación. En general $^{82}$, una apelación continúa al siguiente nivel de juez civil (juez de distrito para el juez de circuito ${ }^{83}$, "master" al juez de la Corte Superior, o juez de circuito al juez de la Corte Superior, o juez de la Corte Superior a la Corte de Apelación) ${ }^{84}$.

Las Reglas especifican los criterios que regulan la decisión sobre la concesión del permiso para apelar: "Elpermiso para apelarpuede darse sólo cuando: (a) el tribunal considera que la apelación tendría posibilidades reales de éxito, $o$ (b) existe alguna otra razón convincente por la cual la apelación debe ser escuchada"s5. Estos criterios proporcionan un filtro para evitar que el sistema de apelación se obstruya por pérdidas de tiempo, apelaciones insustanciales, sin esperanza, infundadas y $\operatorname{costosas}^{86}$.

Si la solicitud inicial de admisión se realiza ante un tribunal inferior,

${ }^{79}$ CPR. 52.3 (1), excepto decisiones que afecta la libertad de las personas; en particular, un permiso para apelar es requerido para ciertas indagaciones que han sido incumplidas; sin embargo, existe un derecho para apelar sin que se requiera su calificación, si hay una decisión para encarcelar una persona por desacato; para estas dos últimas situaciones véase, "Masri v. Consolidated Contractors International Co" SAL [2011] EWCA Civ 898; [2012] 1 WLR 223, construing CPR 52.3 (1) (i).

${ }^{80}$ CPR. 52.4 (2); apelaciones extemporáneas excepcionalmente serían permitidas, "Smith v. Brough" [2005] EWCA 261; [2006] CP Rep 17.

${ }^{81}$ CPR. 52.6 (1), (2).

${ }^{82}$ Existen reglas especiales que permiten algunas apelaciones para subir el nivel de apelación y tener una vía rápida para la Corte de Apelaciones, o incluso la Corte Suprema del Reino Unido

${ }^{83}$ Por ejemplo, "Barnstable Boat Co v. Jones" [2007] EWCA Civ 727; [2008] 1 All ER 1, pp. [1] a [6].

${ }^{84} \mathrm{PD}(52)$.

${ }^{85}$ CPR. $52.3(6)$.

86 "Colley v. Council for Licensed Conveyancers" [2001] EWCA Civ 1137; [2002] 1 WLR 160, per Sir Andrew Morritt, "Existe, entonces, un filtro para detener propuestas de apelación que no tengan una real perspectiva de éxito y donde no hay otra razón imperiosa para que sea escuchada. Sin embargo, por supuesto, este filtro puede ser descrito como una restricción del derecho de una persona para apelar, esto es, en nuestro juicio, no una restricción, del todo, al acceso de las personas, por el contrario, ellos tienen el derecho positivo a la corte y presentar su caso. No hay una restricción sustancial -y no una intrinsecamente injusta restricción - del derecho de apelar, desde que no no hay razón, en justicia, de porqué una persona debería estar facultada para ocupar el tiempo de la corte, y poner a la parte contraria a asumir los gastos y problemas, en proseguir una apelación que 
y esta es rechazada, una nueva solicitud de permiso se puede hacer ante la Corte de Apelación ${ }^{87}$. La solicitud de admisión directamente ante la Corte de Apelación normalmente y en un primer momento, sólo se realiza por escrito $^{88}$. Si la Corte niega el recurso en esta etapa (aplicando los mismos criterios) ${ }^{89}$, el recurrente puede solicitar (dentro de los siete días luego de notificada la resolución que rechazó la petición escrita) que vuelva a revisarse la admisibilidad pero esta vez en una audiencia oral ${ }^{90}$. Para racionalizar el proceso de admisibilidad en la Corte de Apelaciones, hay una excepción: si el es rechazado por dicho tribunal en la fase escrita, y la Corte de Apelación considera que la aplicación es totalmente infundada, puede dictar una resolución indicando que no habrá lugar a la audiencia ${ }^{91}$.

La decisión de inadmisibilidad no exige explicaciones detalladas de la Corte $^{92}$. Por otra parte, no puede haber una apelación contra una decisión de inadmisibilidad del recurso ${ }^{93}$ (como la Corte de Apelación lo ha enfatizado con frecuencia $)^{94}$. Y entonces, no hay otra oportunidad para volver a reabrir el requerimiento de admisibilidad del recurso una vez que ha sido

no tiene una perspectiva real de éxito y donde no existe otra razón imperiosa para que la apelación sea oida".

${ }^{87}$ CPR. 52.3 (3).

${ }^{88}$ Practice Direction (52) 4. 11.

${ }^{89}$ CPR. $52.3(6)$.

${ }^{90}$ CPR. 52.3 (4). Senior Master Turner (Cambridge seminar 6 February 2012) ha notado que la audiencia para el permiso sería de duración limitada; el abogado debe ser sucinto y directo al punto; si la otra parte está ausente, el abogado debe recordar su deber de llamar la atención a cualquier autoridad o factores adversos a sus propias peticiones.

${ }^{91}$ CPR. 52.3 (4) (A).

92 "North Range Shipping Ltd v. Seatrans Shipping Corporation" [2002] 1 WLR 2397, CA, [21] y [22], que cita dos decisiones de la Comisión Europea de Derechos Humanos, "X v. Federal Republic of Germany" (1981) 25 DR 240 ECommHR; "Webb v. UK" (1997) 24 EHRR CD 73 ECommHR (El caso Webb atañe al rechazo del permiso de apelación del Consejo Secreto de la Jurisdicción Alternativa Occidental).

${ }^{93} \mathrm{~S} 54$ (4), Access to Justice Act 1999, "Una apelación no puede ser hecha contra una decision de una corte bajo esta sección por dar o rechazar el permiso (sin embargo, esta sub sección no afecta ningún derecho bajo las reglas de la corte de hacer otras solicitudes de permiso para la misma u otras cortes) ". PD (52), paragráfo 4.8 señala que, "no hay apelación de la decision de la corte de apelación que permite o rechaza apelar para esa corte”, Véase, "Riniker v. University College London" [2000] 1 WLR 13, CA, [6] y [10] a [12].

${ }^{94} \mathrm{La}$ Corte de Apelación ha enfatizado este punto en, "Tanfern Ltd v. CameronMacDonald" [2000] 1 WLR 131, [20]; "Clark v. Perks" [2001] 1 WLR 17, [21]; "Jolly v. Jay" [2002] EWCA Civ 277, [17]; "Bulled v. Khayat” [2002] EWCA Civ 804; [2002] CP Rep 63, [9] a [11]; "Moyse v. Regal Partnership Ltd" [2004] EWCA Civ 1269; [2005] CP 9, [31], Brooke LJ 
rechazado por la Corte de Apelación. El semáforo se mantendrá en rojo: el caso no podrá continuar más allá.

\section{EXPANSIÓN MODERNA DE LA MEDIACIÓN}

En Inglaterra, el empleo de la mediación ha aumentado, incluso en el corazón de las disputas comerciales ${ }^{95}$. La mediación se entiende mejor ahora por las empresas y organizaciones.

La expansión de la mediación no se limita a Inglaterra. La Directiva europea sobre mediación $(2008)^{96}$, ya implementada en Inglaterra ${ }^{97}$, refleja el auge pan-europeo y, en verdad, mundial de esta técnica.

El aumento de la mediación es, en gran parte, atribuible a seis factores: $i$ ) el reconocimiento de las potenciales partes de un conflicto, de que el resultado de los procedimientos judiciales es impredecible; $i$ ) los procesos judiciales son una fuente de gastos, retrasos, y ansiedad; iii) los procedimientos judiciales ofrecen poca participación directa para las partes, a diferencia de los representantes legales; iv) la sentencia normalmente recompensa con la victoria al único ganador; $v$ ) el juicio es la justicia pública, visible para la humanidad en general; y $v i$ ) la litigación es antagónica, de hecho es una guerra privada, incluso si los jueces pretenden que esta se rija por normas y convenios conciliatorios diseñados para hacer más viable la contienda.

Un factor principal de conducta es escapar del agobiante costo formal del litigio judicial (sobre el cual véase más adelante), o del arbitraje complejo. Ambas formas de resolución de controversias, litigación judicial y arbitraje, siguen siendo medios costosos y problemáticos para determinados tipos de disputas civiles. Debe tenerse presente que los costos y gastos están en primer plano en la mente de la mayoría de la gente cuando el litigio se muestra como una alternativa remota. Ciertamente, en Inglaterra, el aumento de la mediación, especialmente en las disputas de elevada cuantía, es, en gran parte, atribuible a las costas que generan los procedimientos judiciales tradicionales. El propio Bill Gates, y otros modernos descendientes de Croesus, dudarían

${ }^{95}$ Mackie, K. - Miles, D. - Marsh, W. - Allen, T., The ADR Practice Guide (3a edición, London, Tottel, 2007), especialmente los capítulos $5^{\circ}, 6^{\circ}$ y $7^{\circ}$; ANDrEws, Neil, cit. (n. 14), cap. $11^{\circ}$; ANDREws, Neil, Contracts and English Dispute Resolution (Tokyo, 2010), cap. $22^{\circ}$.

${ }^{96}$ Directiva 2008/52/EC del Parlamento Europeo y del Consejo, de 21 de mayo de 2008, sobre ciertos aspectos de la mediación en asuntos civiles y comerciales, Official Journal L 136, 24/05/2008 P 0003-0008. Trocker, N. - DeLuca, A. (editores), La mediazione civile all luce della Direttiva 2008/52/CE (Firenze, Firenze University Press, 2011).

${ }^{97}$ Cross-Border Mediation (EU Directive) Regulations 2011/1133. 
en correr el riesgo de involucrarse en prolongadas demandas y reclamos complicados en los Tribunales Superiores.

Además, hay un prejuicio oficial contra los procedimientos judiciales. Los protocolos previos a la acción (que vimos arriba) establecen ${ }^{98}$ :"las etapas iniciales deben ser, usualmente el último recurso, $y$, los procesos no deben iniciarse cuando aun es posible arribar a un acuerdo. A pesar de que los ADR no son obligatorios, las partes deben considerar si algún tipo de procedimiento de ADR puede permitirles resolver el asunto sin necesidad de iniciar un proceso. El tribunal podrá exigir pruebas de que las partes consideraron alguna forma de $A D R$ "99.

La mediación es también atractiva para los funcionarios públicos deseosos de equilibrar las cuentas del Tesoro Público. Es obvio que el gasto de una mediación exitosa será mucho menor que el costo de procedimientos judiciales prolongados (las tasas judiciales no cubren el gasto público total del financiamiento necesario para el sistema de tribunales civiles). El Gobierno (Ministerio de Justicia para Inglaterra y Gales), anunció en febrero de $2012^{100}$, tras un proceso de consulta $(2011)^{101}$, que le gustaría introducir una remisión automática a la mediación para todas las demandas de menor cuantía dentro del sistema de los juzgados del condado o distrito. Durante este proceso de consulta, los jueces hicieron hincapié ${ }^{102}$ en que esto no debería ser un sistema obligatorio de mediación, sino simplemente un sistema que inste a los litigantes a tomar contacto con el servicio de mediación a fin de considerar la posibilidad de mediación en relación con su controversia. El Gobierno aceptaría esta aclaración.

En resumen, Inglaterra va por el camino de una exploración en lugar de la imposición obligatoria de mediación obligatoria en los litigios de escasa cuantía. Afortunadamente, el servicio de mediación dentro del sistema de

${ }^{98}$ Andrews, Neil, English Civil Procedure (Oxford, Oxford University Press, 2003), 3. 13 to 3. 18, 23.07, 26.63-26. 66; para un studio empírico, Goriely, T. Moorhead, R. - Abrams, P., More Civil Justice? The Impact of the Woolf Reforms on Pre-Action Behaviour (Law Society and Civil Justice Council, 2001).

${ }^{99}$ Practice Direction, Pre-action Conduct, par. 8. 1

${ }^{100}$ Resolución de Disputas en las Cortes del Condado p 11, recomendación 24 (febrero de 2012) http,//www. official-documents. gov. uk/document/cm82/8274/8274. pdf

${ }^{101}$ Resolviendo disputas en las cortes del condado, creando un sistema simple, rápido y más proporcional (CP 6/2011, Ministro de Justicia Cm 8045) (29 de marzo 2011).

${ }^{102}$ Resolviendo disputas en las cortes del condado Respuesta del Lord Chief Justice and the Master of the Rolls en nombre del Judicial' (2011), pp 14-15 (http,//www. judiciary. gov. uk/NR/rdonlyres/CCA63782-89BA-49D4-8543-63C16397DB73/0/ lcjmrresponsesolvingdisputescountycourt. pdf) 
pequeñas causas es gratuito. Además, no sería necesaria la comunicación cara a cara, porque telefónicamente sería la forma habitual de comunicación ${ }^{103}$.

Pero hay escépticos golpeando los tambores de los "derechos", la "ayuda social" y la "perfecta justicia procesal", algunos se oponen al crecimiento de la mediación ${ }^{104}$. La esencia de su oposición es que la mediación es un fenómeno insidioso, que el Gobierno está promoviendo por razones de parsimonia (ahorrando gastos en el sistema más caro de los tribunales de justicia), y que los acuerdos mediados tienen la aptitud de menoscabar los verdaderos derechos de las personas.

Hazel Genn (University College, Londres) ${ }^{105}$, en sus conferencias Hamlyn de 2008, criticó el supuesto de que la mediación pueda ofrecer "justicia”. Ella prefiere la visión según la cual la mediación supone la pérdida de la oportunidad de recibir justicia sustantiva por medio del sistema judicial: "Lo que la mediación está ofreciendo es simplemente la oportunidad para descontar [acciones legales], para ahorrarse la presunta miseria e incertidumbre del proceso de adjudicación" ${ }^{106}$. Ella cuestiona si esta debiera ser la política del gobierno para aumentar el negocio de los mediadores y reducir los números de casos de los tribunales ${ }^{107}$.

${ }^{103}$ Resolviendo Disputas en las Cortes de Condado [...], par. 164 (February 2012) http,//www. official-documents. gov. uk/document/cm82/8274/8274. pdf

${ }^{104}$ Genn H., Judging Civil Justice (Cambridge, Cambridge University Press, 2010), caps. $1^{\circ}$ a $3^{\circ}$; Genn, H., Understanding Civil Justice, en Current Legal Problems, 50 (1997), pp. 186-187; y Murray, Peter, The Privatization of Civil Justice (2007) 12 en Zeitschrift ür Zivilprozess International, 12 (2007), pp. 283-303; Murray, Peter, Mediation and Civil Justice, A Public-Private Partnership?enZeitschrift ür Zivilprozess International, 14 (2009), p. 241; Thornburg, E., Reaping What we Sow, Anti-Litigation Rhetoric, Limited Budgets, and Declining Support for Civil Courts, en Civil Justice Quarterly, 30 (2011),p. 74

${ }^{105}$ Genn, H., Judging Civil Justice (Cambridge, Cambridge University Press, 2010), cap. $3^{\circ}$.

${ }^{106}$ Cit. (n. 105), p. 119.

${ }^{107}$ Cit. (n. 105), 125, "[...] hay una interdependencia entre las cortes como promotoras de reglas respaldado por el poder coercitivo, y la práctica de ADR y de los acuerdos en general. Sin el respaldo de la amenaza de coerción, las partes en disputa no podrán ser llevadas a una mesa de negociación. La Mediación sin la amenaza de una determinación judicial creíble, es el sonido de una sola mano aplaudiendo. Un sistema de justicia civil de buen funcionamiento debería ofrecer una opción de métodos de resolución de conflictos". Y agrega: "Necesitamos cortes civiles modernas y eficientes, con procedimientos apropiados que ofrezcan un proceso accesible para aquellos que elijan una determinación judicial. Esto no es imposible. Sin embargo, requiere el reconocimiento del valor social y económico de la justicia civil, y un reconocimiento que algunos casos necesitan ser adjudicados, y una visión para la reforma que se dirija a los defectos percibidos más que un simple manejo de casos". 
Otro adversario de la fiebre moderna hacia la justicia privatizada es Owen Fiss (Escuela de Leyes de Yale). En su polémica “Against Settlement" (1984), escribió: "Los arreglos son para mí el análogo civil del 'plea bargain': El consentimiento es a menudo obtenido mediante coacción; el acuerdo puede ser urgido por alguien sin autoridad [...]. Aunque la lista de casos se recorta, la justicia podría no ser lograda”. Fiss agregó: “Al igual que el 'plea bargaining, el arreglo es una capitulación condicionada por la sociedad de masas y no debiera ser ni alentada ni alabada"108.

Sin duda, la alternativa de los acuerdos no es perfecto. Las posibles objeciones a los acuerdos (incluidos los acuerdos mediados) son ${ }^{109}: i$ ) las partes que celebran acuerdos pueden no comprender plenamente sus respectivas posiciones; $i$ ) las partes pueden estar significativamente en desigualdad de diversas maneras ${ }^{110}$; iii) una de las partes podría haber procurado la solución mediante un trato poco limpio $\left.{ }^{111} ; i v\right)$ una parte con derechos civiles

${ }^{108}$ Yale Law Journal (1984), p. 1073, reimpreso en Galligan, D. (editor), Procedure (Dartmouth, 1992), capítulo 16º ; véase también, Fiss, O., The Law As It Could Be (New York, 2003). Para referencias al debate que generó en los Estados Unidos el artículo de Fiss de 1984, véase, Fiss, O. - Resnik, J., Adjudication and Its Alternatives (New York, Foundation Press, 2003), pp. 481 y 488; y también, Resnik, J., For Owen M. Fiss, Some Reflections on the Triumph and Death of Adjudication, en Miami University Law Review, 58 (2003), p. 173.

${ }^{109}$ Para una colección conveniente de literatura dirigida a este punto: GenN, H Understanding Civil Justice, en Current Legal Problems, 50 (1997), pp. 186-187

${ }^{110}$ GenN, ibíd., p. 179, ha dicho, “[...] estudios destacados [...] las formas en las cuales el poder influencia el resultado de las negociaciones de los acuerdos [...]. Factores que son importantes son, inteligencia legal obtenida de los abogados y expertos adecuados; recursos financieros-pagando por el [mismo], y tener la capacidad psicológica, social, y económica para soportar los litigios". Véase también, Genn, H., Hard Bargaining, Out of Court Settlement in Personal Injury Actions (Oxford University Press, 1987) y la crítica de ANDrews, Neil, en Current Legal Problems (1989), p. 506; y otros estudios citados por GenN (1997) ibíd. También se puede ver, GenN, H., The Paths to Justice, What People Do and Think About Going to Law (Oxford, Hart, 1999); Genn, H., Court-Based ADR Initiatives for Non-Family Civil Disputes, The Commercial Court and the Court of Appeal (Informe de Investigación del Departamento de Asuntos Constitucionales 1/2002, 2002), visible en www. hmcourts-service. gov. uk/ docs/adr_initiatives. pdf (la última pieza examinada resumida en la Sección 5 del autor del artículo en la corte Comercial y case-management).

${ }^{111}$ Por ejemplo en algunos casos "an aggrieved party to a compromise 'threw the contractual book' at the opponent, in an attempt to overturn the compromise", "Halpern v. Halpern" ( $\mathrm{N}^{\circ} 2$ ) [2007] EWCA Civ 291; y, "distribution of estate among family members; allegation that not all relevant assets were revealed and that the compromise should be regarded as vitiated on numerous suggested grounds"; ver el informe [2007] 3; todos en ER 478 relacionados con aspectos específicos del caso; puede consultarse la versión en línea, en p. [1] y ss. Para los numerosos desafíos contractuales; confrontar ello 
completamente reconocidos no debería reducirlos por un acuerdo ${ }^{112} ; v$ ) la evaluación de los "méritos" debe ser mesurada, precisa y rigurosa ${ }^{113}$; y vi) la búsqueda pública de luz en el juicio debería ser destacada sobre las graves y excepcionales equivocaciones.

Como Sir Jack Jacob escribió y refrendó en 1985 el ideal del libre acceso a los tribunales para la más amplia gama de conflictos, antes de que el movimiento ADR. generara un notorio impacto en la corriente principal de la justicia civil inglesa:"Debería ser un objetivo fundamental de la justicia civil abrir las puertas de las salas de justicia y proporcionar procedimientos adecuados y efectivos métodos y medidas, prácticas y procedimientos, ayudas y recursos, para hacer frente a todas las reclamaciones y quejas justiciables". Agregó: “Tal objetivo produciría una mayor armonía y concordia en la sociedad y aumentaría la comprensión y el respeto de la comunidad por la ley y el sistema de justicia civil"114.

Pero esta visión centrada en el tribunal parece discutible. Inglaterra no ha adoptado el objetivo de Jacob de "total litigación en audiencia pública”. En cambio, los cimientos del moderno sistema de justicia civil son: evitar los

con la alegación de que un acuerdo mediado puede ser obtenido mediante coercion. "Farm Assist Limited (in liquidation) v. The Secretary of State for the Environment, Food and Rural Affairs" (N² 2) (2009) [2009] EWHC 1102 (TCC); [2009] BLR 399; 125 Con LR 154

${ }^{112}$ Una de las ansiedades de Jeremy Bentham, Roberts, S., Settlement as Civil Justice, en The Modern Law Review, 63 (2000), pp. 739 y 743 n. 11; Twining, W., Alternatives to What? en The Modern Law Review, 56 (1993), pp. 380 y 384 (examinando varios teóricos del proceso civil, notablemente, Bentham, Llewellyn, Fuller, y Damaska).

${ }^{113}$ Para una estimulante explicación de exactitud y legalidad, JoLowicz, J. A., The Dilemmas of Civil Litigation, en On Civil Procedure (Cambridge, Cambridge University Press, 2000), cap. $4^{\circ}$.

${ }^{114}$ JACOB, J. I. H., Justice Between Man and Man, en Journal of Legal Education, 34 (1984), p. 268 (citado en Genn, H., Understanding Civil Justice, en Current Legal Problems, 50 (1997), pp. 185-186; Genn sugiere que "nuestra futura prosperidad tiene más que ver con que está pasando en las oficinas e industrias en el Lejano Oriente que con si las vías rápidas alcanzarán estos objetivos”. Cfr. también la declaración de Jacob en The Reform of Civil Procedural Law (London, 1982), pp. 125 y 126-127, "En una sociedad civilizada, no deberían existir espacios de barreras a la justicia, ni acceso a la justicia de segunda clase, tanto como no debería existir una justicia de segunda clase" (reimpresión de su contribución para Cappelletti, M. - Garth, B., Access to Justice, a World Survey (Giuffrè - Sijthoff, 1978), I, 1; y la última declaración de Jacob en The Fabric of English Civil Justice (1987), p. 277, “[...] debería existir, no solo igualdad ante la ley sino que igualdad de acceso al derecho y los servicios legales...semejante para ricos y pobres y aquellos de medios moderados, y que tal acceso debería extenderse a todos los reclamos civiles y defensa en todos los niveles del proceso judicial, sin considerar la naturaleza de la disputa o reclamo o de la pretensión o remedio solicitado". 
litigios; fomentar los acuerdos previos al juicio; mantener sólo un pequeño goteo de casos que lleguen a audiencia de juicio.

No obstante, hay, por supuesto, un elemento de verdad en la afirmación de que sería lamentable si la justicia fuera canalizada a menudo subterráneamente. De hecho, sería lamentable si las cosas siempre pudieran estar protegidas de la vista pública por un acuerdo de último minuto diseñado para evitar el escándalo o vergüenza. He aquí algunos ejemplos tomados de la moderna Gran Bretaña: Una mujer mayor, policía, se queja de que su promoción en el escalafón ha sido obstaculizado por discriminación sexual ${ }^{15}$; una familia desea demandar por el suicidio de su hijo dentro de las fuerzas armadas británicas al ser el resultado del "bullying" de sus compañeros soldados ${ }^{116}$; un vendedor de autos establece un plazo de garantía estándar para la reparación de vehículos nuevos y luego lo emplea en forma engañosa para declarar haber sufrido una pérdida fundado en una causa ya insostenible en materia de Derecho de la Libre Competencia ${ }^{117}$; un propietario, una gran organización benéfica, no ha logrado mantener su propiedad en buen estado, a pesar de quejas similares de una gran cantidad de inquilinos ${ }^{118}$.

A veces, se incluyen cláusulas que tienen por objeto excluir el acceso formal a los tribunales o justicia estatales. Así, en "Clyde \& Co v. Bates van Winkelhof” (2011) ${ }^{119}$ la Corte Superior inglesa rehusó mantener una cláusula que requería a un abogado de un estudio jurídico remitir los conflictos laborales a la mediación y luego al arbitraje, en lugar del sistema público de tribunales laborales. No obstante esta cláusula el abogado del trabajador había presentado un recurso ante un Tribunal Laboral. Se alegaron contra el estudio jurídico diversos incumplimientos legales que violaban el derecho de igualdad. La Corte Superior sostuvo que la queja presentada ante el Juzgado Laboral estaba correctamente interpuesta: en este contexto, la ley ${ }^{120}$ impide

${ }^{115}$ Véase el asunto "Halford", julio de 1992, examinado en ANDrews, Neil, Principles of Civil Procedure (London, 1994), p. 26

${ }^{116}$ Tales reclamos han recibido publicidad, para un comentario del Parlamento en 2006 sobre un informe QC dentro de un conjunto de incidentes http,//www. publications. parliament. uk/pa/ld199900/ldhansrd/pdvn/lds06/text/60329-05. htm

${ }^{117}$ Típicamente compradores en talleres como clientes, al no tener la pieza mecánica cambiada el logo del fabricante, a pesar de que se parte que el fabricante también emplea el "logo" con la misma finalidad de especificación del producto; consúltese la Oficina de los comentarios de ComercioJusto enhttp,//www. oft. gov. uk/News/Press+releases/2003/ $\mathrm{PN}+170-03$. htm

${ }^{118}$ Ejemplos por mencionar son muchos como "English Churches Housing Group v. Shine" [2004] EWCA Civ 434

119 [2011] EWHC 668 (QB), Slade J

${ }^{120}$ Equality Act 2010, s 120 y Equality Rights Act 1996, s 203 
que un empleado de 'subcontratación” sea excluido de este sistema abierto y público de adjudicación.

\section{LA AUTO-CONFIADA MARCHA DEL ARBITRAJE COMERCIAL}

Los dos principales puntos de diferencias entre la litigación ante un tribunal estatal y el arbitraje comercial son: en primer lugar, el litigio judicial implica una adjudicación pública, mientras que el arbitraje es una forma privada y confidencial de justicia; en segundo lugar, los laudos arbitrales rara vez pueden ser impugnados en cuanto al fondo, la regla general es adquirir irrevocabilidad a menos que el tribunal arbitral haya ido más allá de su mandato, esto es, el tribunal arbitral traspasó los términos de la cláusula de arbitraje. Además la "Convención de Nueva York" (1958) ${ }^{121}$ proporciona sólo unas limitadas posibilidades para negar la ejecución de los laudos arbitrales. Sujeto a ello, el arbitraje es bastante similar a la adjudicación por parte de un tribunal de justicia. Se espera que los árbitros demuestren virtudes judiciales de igual respeto para cada parte y paciente evaluación del caso presentado por cada una, y en general sus decisiones deben ser razonadas. Predominantemente, los árbitros aplicarán las normas sustantivas del sistema nacional elegido. En ocasiones, los árbitros podrían ser facultados por las partes para aplicar normas más fluidas, o incluso para diseñar las normas sustantivas a medida que avanzan (esto es posible bajo las normas de arbitraje de Inglaterra ${ }^{122}$, India $^{123}$ y Hong Kong ${ }^{124}$, pero no, por ejemplo en Malasia) ${ }^{125}$.

\section{El incumplimiento de la promesa de someterse a arbitraje.}

La saga del caso "West Tankers" (Tribunal Europeo de Justicia, 2009)126 ha demostrado para las autoridades europeas ${ }^{127}$ la necesidad de apreciar el

${ }^{121}$ Art V, New York Convention on the Recognition and Enforcement of Foreign Arbitral Awards (1958).

12246 (1) (b), Arbitration Act 1996 (England and Wales).

${ }^{123} 28$ (2), Arbitration and Conciliation Act 1996 (India).

${ }^{124} 64$, Arbitration Ordinance 2011 (Hong Kong).

12530 (1) a (3), Arbitration Act 2005 (Malayia).

126 “Allianz SpA etc v. West Tankers" (C-185/07) [2009] 1 AC 1138; [2009] 1 All ER (Comm) 435; [2009] 1 Lloyd's Rep 413; [2009] 1 CLC 96; [2009] ILPr 20; The Times, 13 de febrero 2009.

${ }^{127}$ La posición levantada en el caso "West Tankers" está actualmente bajo revisión por la Comisión Europea, Libro Verde sobre el estudio del Consejo de Regulación (EC) No 44/2001 sobre Jurisdicción, reconocimiento y ejecución de sentencias en asuntos civiles y comerciales, Bruselas, 21 de abril de 2009, COM (2009), solicitud de la Regulación de Bruselas, de como remediar la aparente laguna entre lo que la ECJ ha sostenido y lo que es visto como necesidad práctica para el arbitraje y la comunidad legal de la 
imperativo comercial a fin de que se le conceda a la justicia privada "una oportunidad decente" para florecer. La decisión del Tribunal Europeo de Justicia en "Allianz SpA etc. v. West Tankers, The Front Comor" (2009) 128 ha establecido que los tribunales ingleses ya no pueden emitir un mandamiento "anti-pleito" para restringir que una parte en un arbitraje continúe su prosecución mediante procedimientos judiciales ilegales seguidos en los tribunales de un Estado miembro dentro de la zona jurisdiccional de la UE (es decir, los Estados miembros regidos por el Reglamento de competencia de Bruselas, de 2001) ${ }^{129}$.

En el caso "West Tankers" (2009), el Tribunal Europeo de Justicia llegó a la conclusión de que: "Es incompatible con el Reglamento del Consejo (CE) $N^{\circ} 44 / 2001$ de 22 de diciembre de 2000 sobre jurisdicción, el reconocimiento y la ejecución de resoluciones judiciales en materia civil y mercantil por un tribunal de un Estado miembro que despache una orden para restringir a una persona iniciar o proseguir un procedimiento ante los tribunales de otro Estado miembro sobre la base de que dicho procedimiento sería contrario a un acuerdo de arbitraje".

De acuerdo con esta decisión, un mandamiento anti-pleito, aunque dirigido al litigante más que al tribunal extranjero, indirectamente le quitaría al tribunal extranjero la facultad de decidir sobre su propia competencia en virtud del mismo Reglamento. Esto ofendería el axioma Europeo de que los tribunales de cada Estado miembro al que se someta un asunto civil o

Unión Europea. Siguiendo un proceso de consulta el cual aún continúa, la Unión Europea espera proponer una solución legislativa que pueda proporcionar una excepción para el arbitraje regulado por el Reglamento Bruselas. Cómo funcionará esto, está por ser visto.

128 "Allianz SpA etc. v. West Tankers, The Front Comor" (C-185/07) [2009] 1 AC 1138; [2009] 1 All ER (Comm) 435; [2009] 1 Lloyd's Rep 413; [2009] 1 CLC 96; [2009] ILPr 20; The Times, 13 February, 2009; noted E Peel (2009) 125 LQR 365; Consolo, Claudio, Arbitration and EC Law, an Italian Reaction to the Heidelberg Colloquium (2009) Lis Int'l 102-108; SERIKI, H., Declaratory Relief and Arbitration, The Aftermath of The Front Comor (2010) 7 JBL 541-55 SERIKI, H., Anti-Suit Injunctions, Arbitration and the ECJ, An Approach Too Far? En The Journal of Business Law, 7 (2010), p. 24; Schlosser, Peter, Europe, Is it Time to Reconsider the Arbitration Exception from the Brussels Regulation? en International Arbitration Law Review, 12 (2009) 4; Mourre, Alexis - Vagenheim, Alexandre, The Arbitration Exclusion in Regulation 44/2001 after West Tankers, en International Arbitration Law Review, 12 (2009) 5; Clifford, Philip - Browne, Oliver, Lost at Sea or a Storm in a Tea Cup? Anti-suit Injunctions after West Tankers en International Arbitration Law Review, 12 (2009]; Pullen, Andrew, The Future of International Arbitration in Europe, West Tankers and the EU Green Paper [2009) 5.

${ }^{129}$ Regulación del Consejo 44/2001 de 22 de diciembre de 2001 sobre Jurisdicción y el reconocimiento y ejecución de sentencias en asuntos civiles y comerciales. 
comercial según el Reglamento, debe tener jurisdicción para determinar por sí mismo y de hecho la competencia para conocer el mérito de la controversia planteada ante él ${ }^{130}$.

También la hostilidad del Tribunal Europeo de Justicia para las medidas anti-pleito, podría ser la percepción pragmática que, incluso experimentados jueces de la Corte Superior de Londres pudieren ordenar la cesación de un proceso aun siendo la medida claramente justificada, no contarán con confianza de los tribunales de otros Estados miembros ${ }^{131}$.

Otra razón para el Tribunal Europeo de Justicia para oponerse al mandamiento "anti-pleitos" es la perspectiva posible de conflictos entre órdenes de diversos Estados miembros. Como el Tribunal Europeo de Justicia ha dicho en "Turnerv. Grovit" (2004) 132:"Esta posibilidad no puede ser excluida incluso si una orden judicial habia sido emitida en un Estado contratante, sin embargo, otra decisión podría ser emitida por una corte de otro Estado contratante. Del mismo modo, la posibilidad no se puede descartar que los tribunales de dos Estados contratantes que autorizan tales medidas dicten órdenes conminatorias contradictorias".

\section{Apoyo judicial al arbitraje.}

La tendencia moderna es que los tribunales nacionales sean considerados como benevolentes partidarios de arbitraje, en lugar de hostiles obstaculizadores ${ }^{133}$. En Inglaterra, esta actitud iluminada se ve reforzada por el hecho de que muchos jueces comerciales, antes de su nombramiento, mientras ejercen como abogados, actuaron como tales ante los tribunales de arbitrales y recién luego se incorporaron como miembros de aquellos ${ }^{134}$.

\section{Finalidad.}

El enfoque general de los sistemas de arbitraje nacionales es que los tribunales no pueden anular el laudo "sobre el fondo", ya sea por referencia a las conclusiones de hecho y cuestiones de Derecho. La restricción sobre

${ }^{130}$ Cit. (n. 131) [28], [29], ver el caso "Erich Gasser GmbH v. Misat Srl Case" C-116/02 [2003] 1 ECR 14693; [2005] QB 1; [2004] 1 Lloyd's Rep. 222; "Overseas Union Insurance Ltd v. New Hampshire Co”, Case C-351/89 [1991] 1 ECR I-3317; [1992] QB 434; [1992] 2 All ER 138; [1992] 1 Lloyd's Rep 204.

${ }^{131}$ Observación comunicada al autor en el coloquio Europeo.

132 [2005] 1 AC 101; [2004] ECR I-3565, at [30].

${ }^{133}$ Redfern, A. - Hunter, M., International Arbitration (editado por Blackaby, N. - Partasides, Oxford, Oxford University Press, 2009), 7.04 ss.

${ }^{134}$ Es común que al menos un panel de tres árbitros en un asunto comercial sea presidido por un abogado que lo integra y que tiene una calidad reconocida (abogado "senior"), a menudo el panel estará integrado por abogados de alto rango y experiencia (ya sean abogados o jueces jubilados). 
las cuestiones de hecho es seguida en Inglaterra. Aún, existe una excepción para las cuestiones de Derecho inglés decidida en los laudos arbitrales en que el asiento del tribunal está en Inglaterra, porque aquí no hay mucho margen para obtener el permiso de la Corte Superior para conocer de una apelación ${ }^{135}$. Sin embargo, la Corte Superiores es lenta para la admisión de dicho recurso ${ }^{136}$. Es posible prever para las partes en el arbitraje inglés, por un texto muy preciso ${ }^{137}$, que no existirá posibilidad de interponer algún recurso como la apelación contra el laudo.

${ }^{135}$ Véase la sección 69 (2) (3) de la Arbitration Act 1996 (England and Wales), "La autorización para apelar sólo se dará si el tribunal considera, (a) que la determinación de la cuestión afectará sustancialmente los derechos de una o más de las partes; (b) que la cuestión es una de las que se pidió al tribunal que determine; (c) que, sobre la base de las conclusiones de hecho en la adjudicación (i) la decisión del tribunal sobre la cuestión es manifiestamente errónea, o (ii) la cuestión es de importancia pública general y la decisión del tribunal, al menos deja abierta a serias dudas; $y$ (d) que, a pesar del acuerdo de las partes para resolver el asunto mediante arbitraje, es justo y apropiado en todas las circunstancias para que el tribunal determine la cuestión". Existen muchos casos sobre esta disposición, por ejemplo, "Flaux J in ASM Shipping Ltd of India v. TTMI Ltd of England (The Amer Energy)" [2009] 1 Lloyd's Rep 293, at [17], [18] to [19].

${ }^{136}$ Un informe realizado por Veeder, V. V. y A. Sander, A. (2009) nota que la Corte Comercial, en Londres, consideró 36 solicitudes en 2006, y concedió en 9; en 2007, 58, dejando concedidas 13; en 2008, 57, concediendo 144; lo cual revela un promedio de 50 al año, con 12 concesiones (citado en O'ReILly, M., Provisions on Costs and Appeals, An Assessment from an International Perspective, artículo entregado en la conferencia del Instituto Británico de Derecho Internacional y Comparado, Londres, Febrero de 2010).

${ }^{137}$ Gloster J. en "Shell Egypt West Manzala GmbH v. Dana Gas Egypt Ltd” [2009] EWHC 2097 (Comm) sostuvo que las palabras "final, concluyente y vinculante" solamente señalaban que la adjudicación sería definitiva y vinculante, con carácter de cosa juzgada, es decir, las conclusiones de hecho son vinculantes, por lo que no debería haber ningún litigio sobre las mismas cuestiones de hecho entre las mismas partes. Esto deja la puerta abierta a la apelación ante el Tribunal Supremo sobre una cuestión de derecho (si el permiso para apelar ante el Tribunal Superior se puede obtener de un juez en virtud de la sección 69 (2) (3) de la Arbitration Act 1996). Para excluir esta posibilidad de recurso sobre una cuestión de Derecho inglés, habría que afirmar explícitamente que el laudo no estaría sujeto a apelación u otro recurso. De este modo, las reglas de Corte de Arbitraje Internacional de Londres (LCIA), en su artículo 26. 9, prevé, “Todos los reconocimientos serán definitivos y obligatorios para las partes. Al aceptar un arbitraje conforme a este Reglamento, las partes se comprometen a cumplir el laudo inmediatamente $y$ sin demora (única salvedad del artículo 27 [relativo a la corrección de los laudos del tribunal de arbitraje, a petición de las partes o por iniciativa del tribunal], y las partes también renunciar irrevocablemente su derecho a ningún tipo de apelación, revisión o recurrir a cualquier tribunal estatal u otra autoridad judicial, en la medida en que dicha renuncia puede ser hecha válidamente". 


\section{Exigibilidad.}

Más de 140 países son partes en la "Convención de Nueva York" (1958), lo que facilita el cumplimiento relativamente rápido y directo de laudos (arbitrales) extranjeros. Hay una percepción general de que los laudos arbitrales son más fáciles de cumplir en los sistemas extranjeros que las sentencias de los tribunales.

Pero esto no es siempre así, como se desprende de la reciente negativa de Londres a cumplir un laudo de Paris: "Dallah Real Estate \& Turism Holding Co v. Pakistan” (2010) ${ }^{138}$. En ese caso, la Corte Suprema del Reino Unido sostuvo que un laudo de Paris no podía ser ejecutado en Inglaterra, en virtud de la "Convención de Nueva York" (1958). A su juicio, el tribunal arbitral francés había determinado incorrectamente que el Gobierno de Pakistán era parte en el acuerdo de arbitraje correspondiente. Es justo que haya oportunidad para una "comprobación final" antes que el tribunal competente permita la ejecución de la sentencia contra los bienes del deudor. Pero es un poco vergonzoso que un tribunal francés (Cour d'Appel de París de 2011) ${ }^{139}$ llegara recientemente a la conclusión opuesta sobre la cuestión específica de si el Gobierno de Pakistán era parte. El tribunal francés declaró que lo era. Y entonces consideró que este laudo de París fue acorde con los principios de arbitraje franceses ${ }^{140}$. En cualquier caso, la saga "Dallas" revela que la "Convención de Nueva York" (1958) no siempre es el camino más rápido para la aplicación transfronteriza como los entusiastas del arbitraje comercial internacional habían esperado.

\section{OBSERVACIONES FINALES}

SOBRE EL SISTEMA BINARIO DE JUSTICIA PÚBLICA Y PRIVADA

Mi opinión personal es que la calidad de la justicia obtenida de los tribunales superiores de Inglaterra sigue siendo admirable. Esto puede ser comprobado examinando los informes de las sentencias disponibles en formato digital.

Pero ninguna generalización puede hacerse más allá. Todo lo que se puede

${ }^{138}$ [2010] UKSC 46; [2011] 1 AC 763.

${ }^{139}$ El tribunal de revisión designado a tal efecto en Francia (en Inglaterra es el Juzgado de lo Mercantil), Redfern, A. - Hunter, M., International Arbitration (edición de Blackaby, N. y Partasides, C., Oxford, Oxford University Press, 2009), 10. 21; también notando que, ibíd, que la corte de revisión podría ser otro que el tribunal del lugar en que se haya dictado una, aunque esto es engorroso.

140 "Gouvernement du Pakistan v. Société Dallah Real Estate \& Tourism Holding Co”, Cour d'Appel de Paris, Pôle 1, Ch 1, № 09/28533 (17 February 2011) (www. practicallaw. com/8-505-0043). 
decir con seguridad es que el sistema de justicia civil inglés es caro y probablemente seguirá siéndolo. Por esta y muchas otras razones, los litigantes potenciales, si no pueden resolver sus controversias de forma amistosa, serán proclives a seguir (y de hecho acordar de antemano que sólo perseguirían) la mediación y el arbitraje. De esta manera el sistema judicial es habitualmente pasado por alto por los litigantes comerciales.

Los tribunales ingleses y el gobierno promueven con agrado la idea de que los procedimientos judiciales deben ser considerados como una técnica de "último ratio", no sólo para las disputas de negocios, sino también para las demandas civiles ordinarias realizadas por los ciudadanos.

¿Cómo se debería expresar la relación entre los sistemas públicos y privados? ¿Son sistemas rivales? ¿'Son los sistemas alternativos seleccionados en una fatídica bifurcación del camino, uno de ellos, notoriamente "privada", una autopista con peajes con pagos sustanciales ${ }^{141}$ que se realizan para mediadores y árbitros, y la otra ruta, notoriamente "pública", cuya entrada está condicionada al pago de las costas judiciales)?

Por supuesto, las elecciones están hechas. Pero el sistema de los tribunales no desaparece de la vista porque las partes hayan presentado un caso a arbitraje, o porque han comenzado con una mediación. Del mismo modo, los tribunales reconocen su responsabilidad moderna de facilitar y promover la mediación y el arbitraje, y para dar cumplimiento a acuerdos mediados o laudos arbitrales.

La metáfora de la "bifurcación en la ruta", sugiere erróneamente divergencia y separación. Sería más exacto reconocer el matrimonio de los sistemas públicos y privados en los sistemas de resolución de controversias ${ }^{142}$.

\section{EXCURSUS "IN MEMORIAM"}

Este aporte es en honor a John Anthony Jolowicz (1926-2012), Tony. Jolowicz, fallecido recientemente en Cambridge, fue un destacado jurista en Derecho de la responsabilidad civil, y un pionero en el estudio del Derecho

${ }^{141}$ Una importante calificación es que la mediación dentro del sistema de pequeñas causas es libre y conducida por oficiales públicos. Al tiempo de escribir este artículo (abril de 2012), el sistema de pequeñas causas se refieren a acciones que no exceden las $£ 5,000$ (o $£ 1,000$ en el caso de demandas por daños personales y reclamos de reparación de viviendas por arrendatarios residentes). Sin embargo, el Ministerio de Justicia en Febrero de 2012 anunció el propósito de aumentar el techo de las 10. 000 Libras y un inminente aumento alcanzaría las 15.000 Libras, Resolviendo Disputas en las Cortes del Condado [...], p. 11, recomendación 21 y 22 (Febrero de 2012) http,// www. official-documents. gov. uk/document/cm82/8274/8274. pdf

${ }^{142}$ [2010] UKSC 46; [2011] 1 AC 763. 
procesal civil comparado, con gran formación sobre el sistema inglés y otros extranjeros. Ya comenzó a ser conocido por una serie de estudios incisivos y de gran madurez sobre el derecho de la responsabilidad civil ya en la primera etapa de su carrera académica y luego en el segundo ciclo de su vida se dedicó de lleno al área procesal. Le sobreviven dos hijas, y su esposa Poppy.

El apellido "Jolowicz" es una insignia académica famosa usada por Tony y por su padre, H. F. Jolowicz, que era un abogado distinguido. La esposa de Tony se convirtió en miembro de Derecho del Girton College de Cambridge. Una vez formado como abogado y ejercer brevemente, decide dedicar su vida a explorar los temas jurídicos ya mencionados. Al mismo tiempo que tuvo buen provecho la versatilidad lingüística de la familia: Tony hablaba fluidamente francés y español. Esto le permitió disfrutar de un estrecho contacto con las tradiciones jurídicas de Francia y en diversos países de América Latina. También mantenía un buen contacto con los Estados Unidos de América (a propósito, un estudio a largo y erudito sobre el proceso civil de Estados Unidos en una contribución en honor a Liebman, titulado: Algunos acontecimientos siglo XX en anglo-estadounidense de Procedimiento Civil, en Studi in onore di Enrico Tullio Liebman, 1979).

A pesar de que la señora Jolowicz señala que Tony “odiaba los viajes”, superó este problema y ha visitado varias facultades extranjeras. Asistió puntualmente, en particular, a las reuniones de la Asociación Internacional de Derecho Procesal, en cuyo contexto pude verlo afuera de Cambridge. Fue venerado por los distinguidos miembros de esa academia comparativa. Para esta Asociación puso la sabiduría y entusiasmo. A través de esta comunión de los juristas más sofisticados es que hizo amistades duraderas. Siempre el caballo de trabajo dispuesto para el lado del "Common Law", aceptó muchas invitaciones para escribir informes generales e informes nacionales. Tony volvió hábilmente estas invitaciones en oportunidades estimulantes para generar muchos de sus estudios más penetrantes (por ejemplo, Garantias fundamentales en Derecho procesal civil: England, en Las garantias fundamentales de las partes en Derecho procesal civil de 1973; Partes de interés público y el papel activo del juez (con Mauro Cappelletti), 1975; Memorias de apelación, en Hacia una justicia con rostro humano, 1978; Elpapel de la Corte Suprema de Justicia a nivel nacional e internacional. Un informe general, en Yessiou-Faltsi (editor), El papel de las Cortes Supremas en el ámbito nacional e internacional, 1997).

Es en Cambridge donde (después de la escuela y el Ejército) primero como estudiante de pregrado y postgrado, luego como académico, pasó toda su vida desde 1948 hasta 2012. En los años 1950 y 1960, Tony Jolowicz se estableció como el escritor de libros de texto líder en inglés sobre la materia de responsabilidad civil. Su conocimiento exhaustivo de este tema difícil y 
su capacidad de escribir de manera sucinta y con absoluta precisión aseguró que por la década de 1960 había conquistado esta disciplina (Winfield y Jolowicz sobre actos ilícitos, varias ediciones). Pero por entonces ya se estaba aburriendo (como él mismo admitió en sus entrevistas grabadas en los últimos años, con Lesley Dingle). Era el momento de encontrar algo nuevo y, tal vez, más amplio. El enfoque práctico de Tony sobre lo académico lo llevó a estudiar el proceso civil. Esto lo puso en contacto renovado con Sir Jack Jacob; también fue un miembro abnegado de la Asociación Internacional de Derecho Procesal (Poppy Jolowicz había sido discípula de Sir Jack cuando ella había comenzado a integrar como "barrister" el "Bar" inglés).

Tony Jolowicz apoyó muchas instituciones académicas. Desde 1962 a 1980 fue editor de la Revista de la Sociedad de Profesores de Derecho Público. Se convirtió en presidente en 1986-1987 de la Asociación Británica de Profesores de Derecho. Fue vice-presidente (1994) de la Academia Internacional de Derecho Comparado. Fue decano del Colegio de la histórica y prestigiosa asociación de Grays's Inn (1978). Contribuyó firmemente a diversas propuestas de reformas a la legislación nacional. Fue además un enérgico presidente de la Facultad de Derecho en Cambridge (1982-1984) (su "número dos" durante ese período fue el profesor relativamente joven llamado Christopher Greenwood, quien ahora es miembro de la Corte Internacional).

A pesar de estos logros académicos ilustres (debidamente honrado por el premio de Consejero de la Reina, 1990, y la Légion d'honneur (2002), y varios doctorados honoris causa), Tony era un colega con los pies en la tierra y modesto. Era generoso con su tiempo, para ayudar a los jóvenes investigadores a aprender su oficio. Por encima de todo, él perfeccionó el arte de la presentación de información compleja tanto en forma clara como concisa. Esta capacidad, constantemente perfeccionado, para escribir de forma elegante y concisa (que su padre habría reconocido como un atributo principal de los juristas romanos clásicos) es una característica luminosa de todas las obras de Tony. Odiaba el "padding". Si él no tenía nada que decir, permanecía en silencio. Esa auto-disciplina explica por qué su obra se compone de textos que son consistentemente perspicaces, con iluminación y construidos con fuerza. Evidencia de su notable entusiasmo y la tenacidad es su obra clásica luego de jubilarse: El proceso civil (Cambridge University Press, 2000), también traducida al chino por el Dr. Zeyong Wu, en 2008. No hay duda de que dentro de este impresionante libro se destaca su aporte con destilados de reflexión y estudio. A lo largo de estas páginas, el maestro artesano sigue estando en la parte superior de su juego. Se trata de una obra sin igual. Además de los recuerdos compartidos por la familia, amigos y colegas, y un sinnúmero de referencias personales importantes, este es un libro maduro que parece destinado a perdurar como su monumento. 
Resumen biográfico de John Anthony Jolowicz 1926: Nacido 11 de abril 1940-1944: Escuela de Oundle 1944-1948: Fuerzas de Su Majestad, Royal Army Service Corps 1948-1950: Diploma de Cambridge Derecho 1950: Honores de Primera Clase, la Ley Tripos 1952: Miembro del Trinity College Cambridge 1957-1958: Clasesen Chicago 1957: Matrimonio con Poppy Stanley 1959: Profesor de Derecho de Cambridge 1962-1980: Editor, Revista Sociedad de Profesores de Derecho Público 1972-1976: Bencher de Gray's Inn 1982-1984: Presidente de la Facultad de Cambridge 1983: Lionel Cohen Profesor, Universidad Hebrea 1985: Honorable Dr., Universidad Nacional Autónoma de México 1986-1987: Presidente de la Sociedad de Profesores de Derecho Público 1990:Miembro de excelencia Asociación de Derecho Comparado 2000: Hon. LLD Buckingham 2002: Légion d'Honneur

\section{BibLIOgRAFÍA}

American Law Institute/UNIDROIT'S Principles of Transnational Civil Procedure (Cambridge University Press, 2006).

Andrews Neil, English Civil Procedure (Oxford, Oxford University Press, 2003).

ANDREws Neil, Zuckerman on Civil Procedure (London, 2006).

Andrews, Neil, A New Civil Procedural Codefor England: Party-Control Going, Going, Gone, en Civil Justice Quarterly, 19 (2000).

ANDrews, Neil, Contracts and English Dispute Resolution (Tokyo, 2010).

Andrews, Neil, Development in English Civil Procedure: How Far Can the English Courts Reform their Own Procedure?, en Zeitschrift für Zivilprozess International, 2 (1997).

Andrews, Neil, General Report, en Pellegrini Grinover, A. - Calmon, R. (editores), Direito Processual Comparado: XIII Congreso Mundial de Derecho Procesal (Rio de Janeiro, Editora Forense, 2007).

Andrews, Neil, Principles of Civil Procedure (London, 1994).

Andrews, Neil, The Modern Civil Process (Tubinga, Mohr \& Siebeck, 2008).

Bindman, G., No Expense Spared, en New Law Journal (1992).

Blom-Cooper, L. (editor), Experts in Civil Courts (Oxford, Oxford University Press, 2006).

Cappelletti, M. - Garth, B., Access to Justice, a World Survey (Giuffrè - Sijthoff, 1978). 
Clifford, Philip - Browne, Oliver, Lost at Sea or a Storm in a Tea Cup? Anti-suit Injunctions after West Tankers en International Arbitration Law Review, 12 (2009].

Cranston, R, How Law Works (Oxford, Oxford University Press, 2006).

Dwyer, D., The Judicial Assessment of Expert Evidence (Cambridge, Cambridge University Press, 2008).

Fiss, O. - Resnik, J., Adjudication and Its Alternatives (New York, Foundation Press, 2003).

Fiss, O., The Law As It Could Be (New York, 2003).

Galligan, D. (editor), Procedure (Dartmouth, 1992).

Genn, H Understanding Civil Justice, en Current Legal Problems, 50 (1997).

Genn, H., Hard Bargaining: Out of Court Settlement in Personal Injury Actions (Oxford University Press, 1987).

Genn, H., Judging Civil Justice (Cambridge, Cambridge University Press, 2010).

Genn, H., Court-Based ADR Initiatives for Non-Family Civil Disputes: The Commercial Court and the Court of Appeal (Informe de Investigación del Departamento de Asuntos Constitucionales 1/2002, 2002).

Genn, H., The Paths to Justice: What People Do and Think About Going to Law (Oxford, Hart, 1999).

Getzler, J., Patterns of Fusion, in Birks, P. (editor), The Classification of Obligations (Oxford, Clarendon Press, 1997).

Goriely, T. - Moorhead, R. - Abrams, P., More Civil Justice? The Impact of the Woolf Reforms on Pre-Action Behaviour (Law Society and Civil Justice Council, 2001).

Hazard, G. - Taruffo, M., American Civil Procedure (Yale University Press, 1993).

JACKSON, Rupert, Review of Civil Litigation Costs (London, 2010).

JАСОв, J. I. H., The Fabric of English Civil Justice (Londresm 1987).

ЈАсов, J. I. H., Justice Between Man and Man, en Journal of Legal Education, 34 $(1984)$.

JАСОв, J. I. H., The Reform of Civil Procedural Law (London, 1982).

Jolowicz, J. A., The Dilemmas of Civil Litigation, en On Civil Procedure (Cambridge, Cambridge University Press, 2000).

Larson, T. - Leonardi, D., A Comparative Study of Costs in Defamation Proceedings across Europe (Programme in Comparative Media Law and Policy, Centre for SocioLegal Studies, University of Oxford, December 2008).

Woolf, Lord, Access to Justice: Final Report (1996).

Woolf, Lord, Access to Justice: Interim Report (1995).

Mackie, K. - Miles, D. - Marsh, W. - Allen, T., The ADR Practice Guide (3a edición, London, Tottel, 2007).

McIvor, Claire The Impact of the Jackson Reforms on Access to Justice in Personal Injury Litigation, en Civil Justice Quarterly, 30 (2011).

Mourre, Alexis - Vagenheim, Alexandre, The Arbitration Exclusion in Regulation 44/2001 after West Tankers, en International Arbitration Law Review, 12 (2009) 5.

Murray, Peter, Mediation and Civil Justice: A Public-Private Partnership? enZeitschrift für Zivilprozess International, 14 (2009),

Murray, Peter, The Privatization of Civil Justice, en Zeitschrift für Zivilprozess International, 12 (2007). 
Redfern, A. - Hunter, M., International Arbitration (edición de Blackaby, N. y Partasides, C., Oxford, Oxford University Press, 2009).

ReSNIK, J., For Owen M. Fiss: Some Reflections on the Triumph and Death of Adjudication, en Miami University Law Review, 58 (2003).

Roberts, S., Settlement as Civil Justice, en The Modern Law Review, 63 (2000).

Schlosser, Peter, Europe, Is it Time to Reconsider the Arbitration Exception from the Brussels Regulation? en International Arbitration Law Review, 12 (2009) 4.

SERIKI, H., Anti-Suit Injunctions, Arbitration and the ECJ: An Approach Too Far? en The Journal of Business Law, 7 (2010).

Thornburg, E., Reaping What we Sow: Anti-Litigation Rhetoric, Limited Budgets, and Declining Support for Civil Courts, en Civil Justice Quarterly, 30 (2011).

Trocker, N. - De Luca, A. (editores), La mediazione civile alla luce della Direttiva 2008/52/CE (Firenze, Firenze University Press, 2011).

Trocker, N. - Varano, V. (editores), The Reforms of Civil Procedure in Comparative Perspective (Torino, 2005).

Twining, W., Alternatives to What? en The Modern Law Review, 56 (1993).

Zuckerman, A. - Cranston, R., The Reform of Civil Procedure: Essays on 'Access to Justice' (Oxford, Oxford University Press, 1995).

Zuckerman, A. A. S, en Andenas, M. - Andrews, N. - Nazzini, R. (editores), The Future of Transnational Commercial Litigation: English Responses to the American Law Institute/UNIDROIT Draft Principles and Rules of Transnational Civil Procedure (London, British Institute of Comparative and International Law, reimpresión 2006).

Zuckerman, A. A. S, Litigation Management under the CPR: a Poorly-used Management Infrastructure [...], en DWyER, D. (editor), The Civil Procedure Rules: Ten Years On (Oxford, Oxford University Press, 2010).

Zuckerman, A. A. S., The Jackson Final Report on Costs-Plastering the Cracks to Shore up a Dysfunctional System, en Civil Justice Quarterly, 29 (2010). 
